\title{
USO DE PLASMA SUÍNO DESIDRATADO POR "SPRAY DRYER" NA DIETA DE LEITÕES DESMAMADOS PRECOCEMENTE
}

\author{
EDUARDO AFONSO FRANDI BUTOLO
}

Dissertação apresentada à Escola
Superior de Agricultura "Luiz de
Queiroz", da Universidade de São Paulo,
para obtenção do título de Mestre em
Agronomia, Área de Concentração:
Ciência Animal e Pastagens.

\author{
P I R A C I C A B A \\ Estado de São Paulo - Brasil \\ Julho - 1997
}




\title{
USO DE PLASMA SUINO DESIDRATADO POR "SPRAY DRYER" NA DIETA DE LEITÕES DESMAMADOS PRECOCEMENTE
}

\author{
EDUARDO AFONSO FRANDI BUTOLO \\ Engenheiro Agrônomo \\ Orientador: Prof. Dr. VALDOMIRO SHIGUERU MIYADA
}

Dissertação apresentada à Escola
Superior de Agricultura "Luiz de
Queiroz", da Universidade de São Paulo,
para obtenção do título de Mestre em
Agronomia, Area de Concentração:
Ciência Animal e Pastagens.

PIR A C I C AB A

Estado de São Paulo - Brasil

Julho -1997 
Dados Internacionais de Catalogação na Publicação (CIP) DIVISÃo DE BIBLIOTECA E DOCUMENTAÇÃO - Campus "Luiz de Queiroz"/USP

Butolo, Eduardo Afonso Frandi

Uso de plasma suíno desidratado por "spray dryer" na dieta de leitões desmamados precocemente / Eduardo Afonso Frandi Butolo. - . Piracicaba, 1997.

$48 \mathrm{p}$.

Dissertação (mestrado) - - Escola Superior de Agricultura Luiz de Queiroz, 1997. Bibliografia.

1. Desmame 2. Dieta animal 3. Leitão 4. Suinocultura 1. Título

CDD $\quad 636.4$

636.08932 


\title{
USO DE PLASMA SUÍNO DESIDRATADO POR "SPRAY DRYER" NA DIETA DE LEITÕES DESMAMADOS PRECOCEMENTE
}

\author{
EDUARDO AFONSO FRANDI BUTOLO
}

Aprovado em: 29.08 .1997

Comissão julgadora:

Prof. Dr. José Fernando M. Menten

ESALQ/USP

Prof. Dr. Dirlei Antonio Berto

FMVZ/UNESP

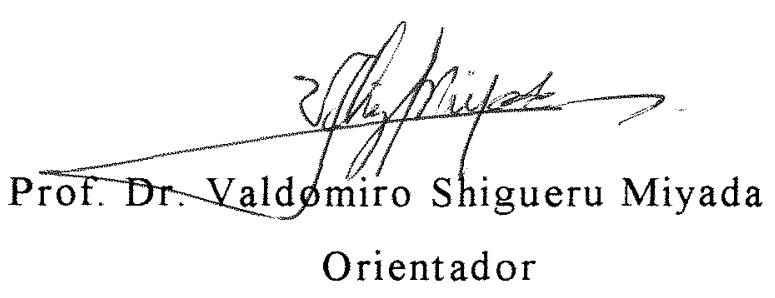


Aos meus pais,

José Eduardo e Maria Augusta,

pela minha formação e incentivo,

DEDICO 


\section{AGRADECIMENTOS:}

Ao prof. Dr. Valdomiro Shigueru Miyada, pela confiança, orientação, amizade, além de seus conhecimentos técnicos;

Ao prof. Dr. Irineu Umberto Packer, pelo auxílio e sugestões nas análises estatísticas;

Aos funcionários do setor de Suinocultura do Departamento de Zootecnia da ESALQ (Srs. Pires e Ventura);

Ao Conselho Nacional de Desenvolvimento Científico e Tecnológico - CNPq, pela concessão da Bolsa durante o curso;

Aos companheiros da SUPREMAIS, que de uma forma ou outra contribuíram para a realização deste;

Ao Sr. Olinto Rodrigues de Arruda, e aos funcionários da Fazenda Água Branca (Denilson, Adalce, João, Nego, Graça), pela ajuda no fornecimento dos animais, sem os quais não seria possivel a realização deste trabalho; 
Aos Srs. Karl Poulsen e Louis Russel da American Protein Corporation - APC, pelo fornecimento dos produtos $e$ as valiosas sugestões.

Aos amigos e companheiros de trabalho, Flávio, Vaguinho, Ademir e Ilmar pela ajuda na confecção das rações experimentais e coleta de dados;

Aos amigos e companheiros de trabalho, Paulo e "Mico", pela ajuda na análise estatistica e montagem das figuras;

A todos aqueles, que de alguma forma, contribuíram para a realização deste trabalho e que por falha da minha memória, não estão aqui citados, o nosso agradecimento. 


\section{SUMÁRIO}

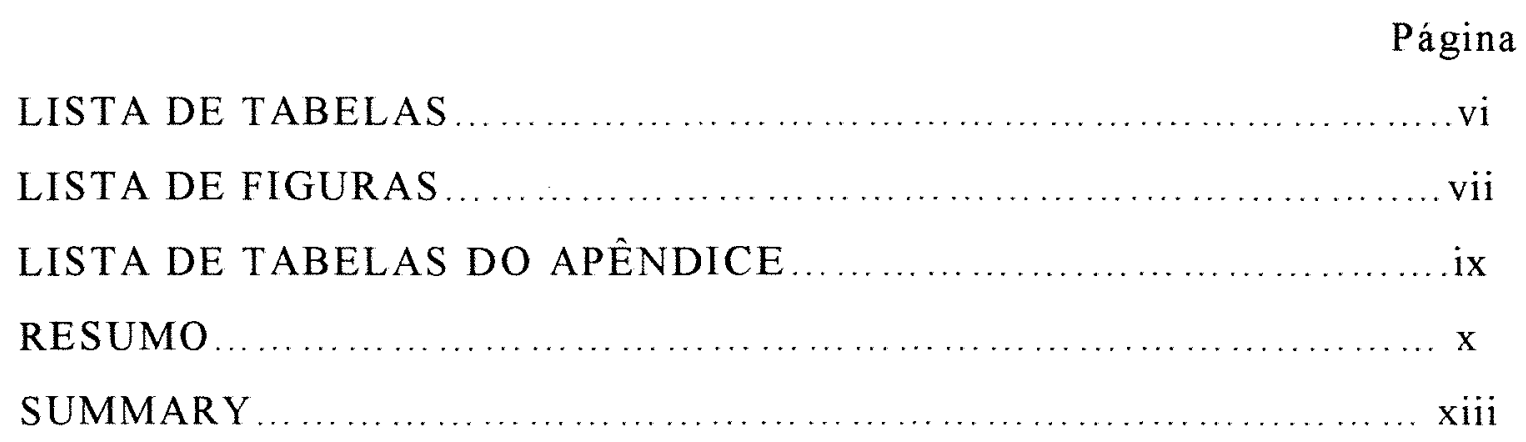

1. INTRODUÇÃO 1

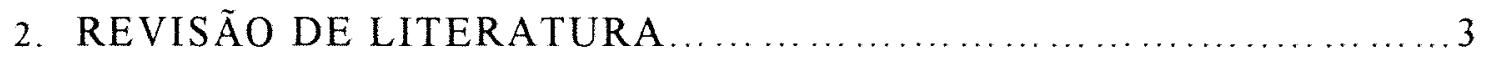

2.1. Fontes de proteína para leitões............................. 3

2.2. Modo de ação do plasma .................................... 9

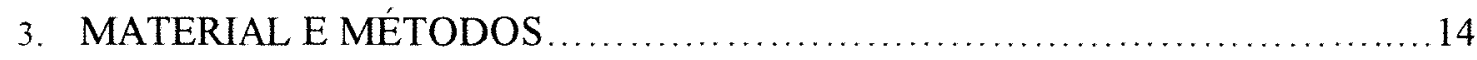

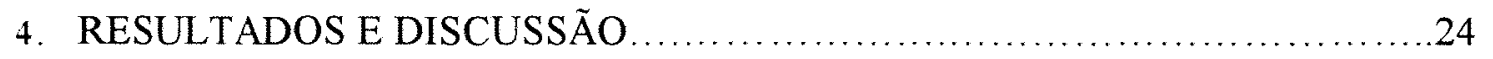

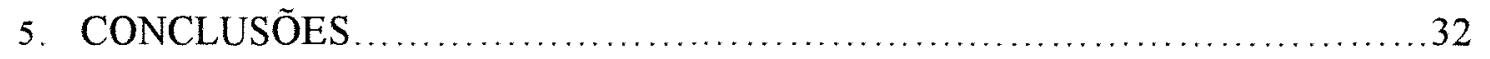

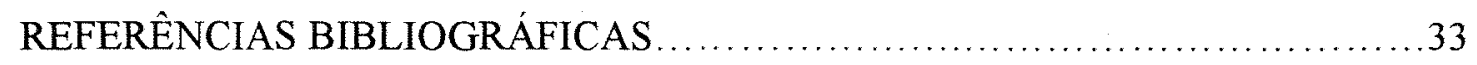

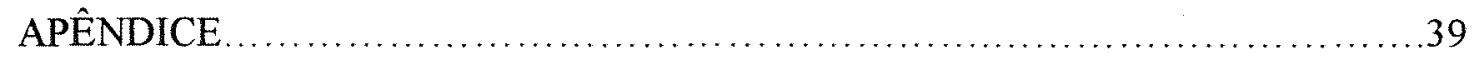




\section{LISTA DE TABELAS}

TABELA N

PÁGINA

1 Composição química e conteúdo energético dos ingredientes................................. 17

2 Composição em aminoácidos dos ingredientes .... 18

3 Composição percentual das rações experimentais-

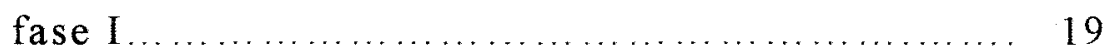

4 Composição percentual das rações experimentaisfase II ...................................... 20

5 Nutrientes calculados das rações experimentais-

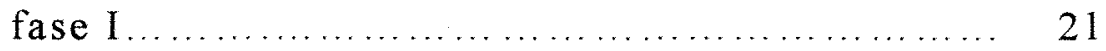

6 Nutrientes calculados das rações experimentais-

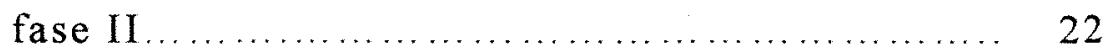

7 Média das características de performance dos leitões em recria alimentados com rações contendo niveis crescentes de inclusão de

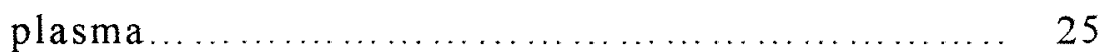

8 Efeito dos niveis crescentes de inclusão de plasma na dieta de leitões em recria sobre o consumo

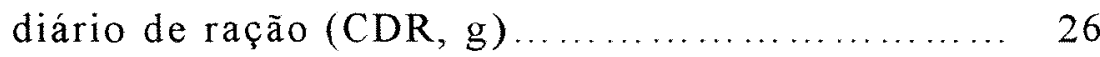




\section{LISTA DE FIGURAS}

FIGURA N ${ }^{\circ}$

PÁGINA

1 Esquema do processamento dos produtos de

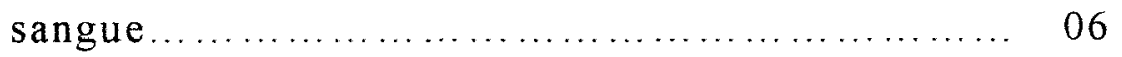

2 Dados de temperatura observados durante o período experimental.......................... 15

3 Efeito dos niveis de plasma sobre o consumo diário de ração (CDR, g) de leitões em recria na primeira semana de experimentação............. 30

4 Efeito dos niveis de plasma sobre o consumo diário de ração (CDR, g) de leitões em recria na segunda semana de experimentação

5 Efeito dos niveis de plasma sobre o consumo diário de ração (CDR, g) de leitões em recria na terceira semana de experimentação.

6 Efeito dos níveis de plasma sobre o consumo diário de ração (CDR, g) de leitões em recria na quarta semana de experimentação.

7 Efeito dos níveis de plasma sobre o consumo diário de ração (CDR, g) de leitões em recria nas duas primeiras semanas de experimentação (0 a 14 dias)

8 Efeito dos níveis de plasma sobre o consumo diário de ração (CDR, g) de leitões em recria nas três primeiras semanas de experimentação $(0$ a 21 dias) 
9 Efeito dos níveis de plasma sobre o consumo diário de ração (CDR, g) de leitões em recria nas quatro semanas de experimentação $\left(\begin{array}{lll}0 & \text { a } & 28\end{array}\right.$

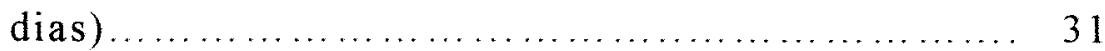

10 Efeito dos níveis de plasma sobre o consumo diário de ração (CDR, g) de leitões em recria nas duas últimas semanas de experimentação (14 a 28 dias) 


\section{LISTA DE TABELAS DO APÊNDICE}

TABELA N ${ }^{\circ}$

PÁGINA

Al Resultados de performance dos leitões em recria na primeira semana experimental

A2 Resultados de performance dos leitões em recria na segunda semana experimental $\quad\left(\begin{array}{llll}7 & \text { a } & 14\end{array}\right.$ dias)

A3 Resultados de performance dos leitões em recria na terceira semana experimental (14 a 21 dias)

A4 Resultados de performance dos leitões em recria na quarta semana experimental $(21)$ a 28 dias)

A5 Resultados de performance dos leitões em recria nas duas primeiras semanas experimentais $\left(\begin{array}{lll}0 & \text { a } & 14\end{array}\right.$ dias)

A6 Resultados de performance dos leitões em recria nas três primeiras semanas experimentais $\left(\begin{array}{lll}0 & \text { a } & 21\end{array}\right.$

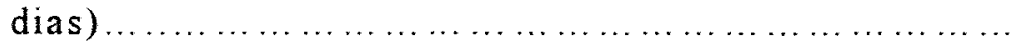

A7 Resultados de performance dos leitões em recria nas quatro semanas experimentais $\left(\begin{array}{llll}0 & \text { a } & 28\end{array}\right.$

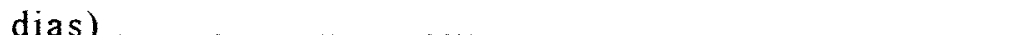

A8 Resultados de performance dos leitões em recria nas duas últimas semanas experimentais $\left(\begin{array}{lll}14 & \text { a } & 28\end{array}\right.$ dias)

A9 Peso médio dos blocos dos tratamentos em cada

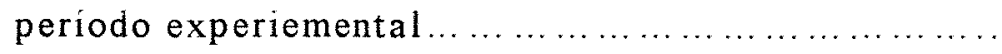




\title{
USO DE PLASMA SUÍNO DESIDRATADO POR “SPRAY DRYER" NA DIETA DE LEITÕES DESMAMADOS PRECOCEMENTE
}

\author{
Autor: EDUARDO AFONSO FRANDI BUTOLO \\ Orientador: Prof. Dr. VALDOMIRO SHIGUERU MIYADA
}

\section{RESUMO}

O presente estudo teve por objetivo avaliar o uso do plasma suíno desidratado por "spray dryer", na dieta de leitões desmamados aos 21 dias de idade, através dos parâmetros de performance. Utilizaram-se 120 leitões, machos e fêmeas, mestiços, provenientes do cruzamento de fêmeas Agroceres com machos terminadores Dalland, com peso médio inicial de $5,75 \mathrm{~kg}$. Na fase I (0 a 14 dias de experimentação) foram testados niveis de $0,2,5,5,0$ e $7,5 \%$ de plasma na dieta. Na fase II (14 a 28 dias de experimentação), todos os leitões receberam uma ração com $2,5 \%$ de plasma e $2,5 \%$ de hemácias, exceto aqueles do tratamento controle. As dietas foram formuladas para conter $1,40 \%$ de lisina, $0,54 \%$ de metionina e $15 \%$ de lactose na fase I e 1,20\% de lisina, 0,42\% de metionina e $8,0 \%$ de lactose na fase II.

A ração e a água foram fornecidas à vontade durante todo o período experimental de 28 dias. Semanalmente, foram feitas pesagens em grupos por repetição e registrados o consumo de ração das baias para cálculo da conversão alimentar. 
O delineamento experimental foi o de blocos completos casualizados, com 5 repetições por tratamento, com 6 animais por baia. Os graus de liberdade do fator nivel de plasma foram desdobrados nos componentes linear, quadrático e cúbico, através dos polinômios ortogonais.

Os niveis de inclusão de plasma proporcionaram resposta linear crescente no consumo diário de ração no período de 0 a 14 dias experimentais $(\mathrm{P}=0,0298 ; 420,458,463,507 \mathrm{~g} ; \mathrm{Y}=422,4286$ $\left.+10,5524 X ; R^{2}=0,86\right)$, porém não apresentou efeito $(P>0,10)$ sobre o ganho diário de peso e conversão alimentar nesse periodo.

Durante a segunda fase de experimentação, 14 a 28 dias, os niveis de plasma na dieta da primeira fase proporcionaram resposta linear crescente no consumo diário de ração $(\mathrm{P}=0,0783 ; 1026,1096$, $\left.1106,1104 \mathrm{~g} ; \mathrm{Y}=1046,1095+9,7962 \mathrm{X} ; \mathrm{R}^{2}=0,57\right)$. A associação de plasma mais hemácias, nesse período, não apresentou nenhuma resposta significativa $(P>0,10)$ nos demais parâmetros avaliados.

No período total de experimentação ( 0 a 28 dias), também foi encontrado uma resposta linear crescente para o consumo diário de ração $(P=0,0376 ; 723,777,784,805 \mathrm{~g} ; \mathrm{Y}=734,2691+10,1743 \mathrm{X}$; $\left.\mathrm{R}^{2}=0,76\right)$ dos animais que receberam dietas com níveis crescente de plasma na primeira fase.

Os resultados do presente experimento evidenciaram que a inclusão de até $7,5 \%$ de plasma desidratado por "spray dryer", em ração pré-inicial, estimula o consumo de ração nas duas semanas subsequentes ao desmame e que esse maior consumo é mantido 
durante a segunda fase ( 14 a 28 dias pós-desmame), quando uma combinação de $2,5 \%$ de plasma com $2,5 \%$ de hemácias foi utilizada na ração inicial. 


\title{
USE OF SPRAY-DRIED PORCINE PLASMA IN EARLY-WEANED PIG DIETS
}

\author{
Author: EDUARDO AFONSO FRANDI BUTOLO
}

Adviser: Prof. Dr. VALDOMIRO SHIGUERU MIYADA

\section{SUMMARY}

An experiment, involving 120 crossbred weanling pigs (Dalland $x$ Agroceres) weaned at 21 days of age and averaging 5.75 $\mathrm{kg}$ initial live weight, was carried out to evaluate the effect of dietary levels of spray-dried porcine plasma (SDPP) on pig performance. Levels of $0,2.5,5.0$, and $7.5 \%$ of SDPP were used in pre-starter diets during 14-day-postweaning period (phase I). Except for control pigs, all other animals were fed a starter diet with $2.5 \%$ of SDPP and $2.5 \%$ of spray-dried red blood cell during 14 to 28 -daypostweaning period. The pre-starter diet (phase I) was formulated to contain $1.4 \%$ lysine, $.54 \%$ methionine, $15 \%$ lactose, while the starter diet (phase II) contained $1.2 \%$ lysine, $.42 \%$ methionine and $8 \%$ lactose.

Feed and water were given "ad libitum" during the 28-dayexperimental period. Pigs were weighed in group and feed intake/pen was registered weekly. 
A randomized complete block design with 5 replications and 6 animals/experimental unit (pen) was utilized. The data were analysed by using a regression analysis.

During phase I ( $d 0$ to 14 postweaning), average daily feed intake increased linearly $(\mathrm{P}=.0298 ; 420,458,463,507$ g $\mathrm{Y}=$ $422.4286+10.5524 \mathrm{X} ; \mathrm{R}^{2}=.86$ ) with increasing spray-dried porcine plasma. Average daily gain and feed conversion was not affected by dietary treatments.

During phase II ( $d 4$ to 28 postweaning), average daily feed intake increased linearly $(\mathrm{P}=.0783 ; 1026,1096,1106,1104 \mathrm{~g} ; \mathrm{Y}=$ $\left.1046.1095+9.7962 X ; R^{2}=.57\right)$ with increasing spray-dried porcine plasma in phase I. The performance of pigs was not affected due the inclusion of spray-dried red blood cells and plasma in phase II diets.

From day 0 to 28 postweaning, average daily feed intake improved linearly $(\mathrm{P}=.0376 ; 723,777,784,805 \mathrm{~g} ; \mathrm{Y}=734.2691+$ 10.1743X; $\left.\mathrm{R}^{2}=.76\right)$ with increasing spray-dried porcine plasma on phase I diets.

The results of these experiment demonstrate that increasing levels of spray-dried porcine plasma increased average daily feed intake during the two weeks after weaning and this effect was mantained in phase II when a combination of $2.5 \%$ plasma and $2.5 \%$ blood cell was utilized. 


\section{INTRODUÇ̃̃̃O}

A demanda por proteina animal a nível mundial cresce constantemente de forma irreversivel, e a carne suina tem expressiva participação no atendimento desta demanda, o que faz necessário um aumento também constante da produção de suinos com a máxima eficiência possivel.

Um dos fatores que tem contribuido para este incremento, além do melhoramento genético, práticas de manejo adequada e maior atenção às práticas de biossegurança, é o sistema intensivo de criação, onde a idade de desmame dos leitões tem diminuído, com a finalidade de aumento da produtividade da fêmea, expressa principalmente como leitegadas por ano e leitões desmamados por fêmea por ano.

O desmame com idade precoce, em torno de 3 semanas de vida ou menos, resulta em problemas como baixo ganho de peso, baixo consumo de alimento, aumento de morbidade e mortalidade em muitas granjas produtoras. 
Fatores como meio ambiente, "status" sanitário, práticas de manejo e a nutrição são fundamentais para o sucesso em programas de desmame precoce. Entretanto, como a nutrição, depois do meio ambiente, é o fator mais crítico em tais programas, levou os nutricionistas a desenvolverem dietas chamadas complexas, sendo as fontes dos nutrientes baseadas na capacidade de digestão do aparelho digestivo ainda imaturo dos leitões.

Por ocasião do desmame, um complexo conjunto de alterações nutricionais, de ambiente e sociais, se instala levando o leitão ao estresse. Do ponto de vista estritamente nutricional, dietas complexas baseadas em ingredientes de alta digestibilidade e qualidade têm proporcionado resultados satisfatórios nas fases iniciais com subsequente melhoria na performance nas fases de crescimento e terminação.

O objetivo deste trabalho foi o de avaliar o uso do plasma suíno seco por "spray dryer", nas dietas iniciais de leitões desmamados aos 21 dias de idade, através dos parâmetros de ganho de peso diário, consumo diário de ração e conversão alimentar. 


\section{REVISÃO DE LITERATURA}

\subsection{Fontes de proteína para leitões}

Devido a limitada capacidade digestiva dos leitões desmamados precocemente, diversas pesquisas foram conduzidas para avaliar a utilização de diferentes fontes protéicas nas dietas destes animais (KATS et al., 1992; FRIESEN et al. 1993; SMITH et al., 1994; RICHERT et al., 1994), uma vez que o desenvolvimento pancreático e enzimático dos leitões é insuficiente antes da sexta a oitava semana de vida (PEKAS, 1991).

A maioria das fontes protéicas avaliadas envolveram proteínas do leite, da soja, de farinhas de peixe, carne e farinha de sangue (GATNAU et al., 1993). Diferentes métodos de processamento foram desenvolvidos para melhorar a qualidade das fontes de proteinas, principalmente da soja, com a finalidade de inativar os fatores antinutricionais e melhorar sua utilização pelos leitões, os quais são muito sensiveis a estes fatores presentes no farelo de soja processado convencionalmente (AUGENSTEIN et al, 1994). 
Segundo GATNAU et al. (1993), foram estudados processos de secagem de fontes protéicas originalmente em estado líquido, prevenindo danos causados pelo calor excessivo, resultando em melhor aproveitamento dos nutrientes pelo animal.

Os produtos derivados de sangue, no passado, sofriam processamento térmico intensivo, com a finalidade de eliminar contaminações biológicas. Esses processos consistiam em secagem por tambor ou rolo secador, os quais resultavam em produtos de qualidade inconsistente quanto à digestibilidade, solubilidade e granulometria, devido a diferenças na condução do processo e manuseio desses subprodutos.

O processamento por "spray dryer" melhorou drasticamente a qualidade e, consequentemente, o uso dessas fontes protéicas na indústria de alimentação, devido à manutenção da integridade ou funcionalidade dos componentes da proteina, bem como a digestibilidade dos amino ácidos, além de não requerer processamento após secagem, pois o tamanho das partículas pode ser controlado pelo emprego do atomizador, evitando as chances de contaminação do produto (KATS et al., 1994a).

O plasma suino desidratrado por "spray dryer" é um subproduto proveniente de abatedouro. O processo começa com a coleta do sangue integral, ao qual é adicionado um anticoagulante, normalmente citrato de sódio (GATNAU et al., 1993). Utiliza-se ainda como anticoagulante, polifosfatos de sódio ou potássio, sais de oxalato de potássio, amônio e fluoreto de sódio, além de agentes quelantes como etilenodiaminotetracetato (EDTA) e heparina 
(SWENSON, 1988; SGARBIERI, 1996). O sangue integral passa então por um processo de centrifugação onde as hemácias são separadas do plasma e os produtos são refrigerados, obtendo-se de $60-65 \%$ de plasma e $35-40 \%$ de concentrado de hemácias (SGARBIERE, 1996). Cada fração do sangue, plasma e hemácias, passa pelo "spray dryer", que consiste na difusão do líquido em uma câmara quente, onde o líquido é transformado em estado sólido muito rapidamente, conservando assim a qualidade da proteína.

Os produtos resultantes são um pó fino de coloração marrom claro, contendo $78 \%$ de proteína (após a remoção de minerais) para o plasma (AP 920), e um pó fino de coloração vermelho escuro com $92 \%$ de proteina para as hemácias (AP 301), conforme ilustrado na Figura 1. O perfil de amino ácidos destes produtos mostram uma concentração alta em lisina, triptofano e treonina, porém concentração relativamente baixa de metionina e isoleucina em relação à lisina (KATS et al., 1994b).

OWEN et al.(1995a) mostraram que a metionina foi o primeiro amino ácido limitante em dietas de alta densidade para leitões, onde se utilizaram o plasma desidratado e a farinha de sangue, devido ao seu conteúdo de metionina em relação à lisina.

As proteínas contidas no plasma são, na maioria, o fibrinogênio, as de alto peso molecular (globulinas), as de peso molecular médio (albuminas) e compostos de baixo peso molecular. As globulinas incluem as frações $\alpha_{1}, \alpha_{2}, \beta_{1}, \beta_{2}$ e $\gamma$-globulinas, sendo que as $\gamma$-globulinas são produzidas pelos linfócitos e células 
plasmáticas e contêm anticorpos denominados imunoglobulinas ( SWENSON, 1988).

GATNAU \& ZIMMERMAM (1990) relataram um aumento no consumo de ração de suínos desmamados precocemente, quando o farelo de soja foi substituido por plasma desidratado ou caseína a nível de $10 \%$ em dietas de milho, farelo de soja e soro de leite. Num segundo experimento, encontraram maior ganho de peso e consumo de ração nas duas primeiras semanas apos o desmame, quando o farelo de soja foi substituido em 10\% pelo plasma, juntamente com a adição de $20 \%$ de soro de leite.

HANSEN et al.(1991) substituiram o leite desnatado pelo plasma desidratado em dietas isolisinicas e isolactósicas e encontraram efeito positivo no ganho de peso e consumo de ração, atribuindo esse efeito ao próprio plasma e não pela substituição do farelo de soja, e que a adição de soro de leite ou lactose maximizou o ganho de peso e o consumo de ração.

GATNAU \& ZIMMERMAN (1991a) trabalhando com dietas onde o nível de inclusão de plasma variou de 0 a $8 \%$, encontraram resposta linear e quadrática para ganho de peso e resposta quadrática para consumo de ração, e eficiência alimentar nas duas primeiras semanas após o desmame. Também encontraram resposta quadrática para consumo de ração, no período de quatro semanas após o desmame. Concluiram que o nível ótimo de inclusão estava em $6 \%$, o qual foi confirmado mais tarde, por GATNAU \& ZIMMERMAN (1992), onde o plasma foi adicionado até o nível de $10 \%$ na ração dos leitões, obtendo uma resposta quadrática, com o 


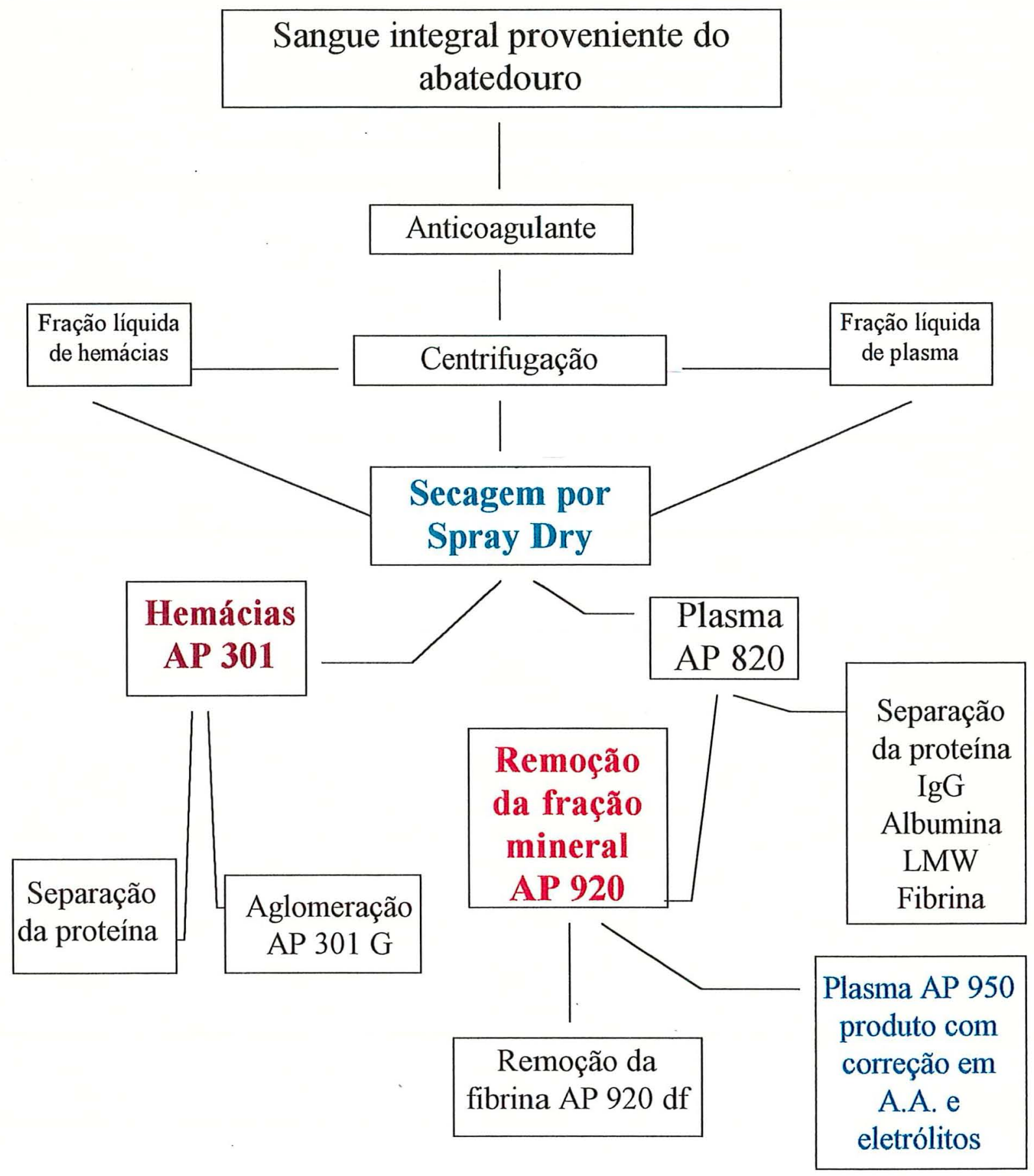

Figura 1. Esquema do Processamento dos Produtos de Sangue. 
máximo de ganho de peso e consumo de ração ao nível de $6 \%$ de inclusão de plasma, no período de quatro semanas após o desmame.

KATS et al. (1994b) encontraram resposta linear para o ganho de peso de leitões até o nível de $10 \%$ de inclusão de plasma na dieta, e uma resposta quadrática para consumo de ração, com o nivel ótimo de $8,5 \%$, até 14 dias após o desmame.

OWEN et al.(1993), trabalhando com dietas contendo plasma de suino desidratado ao nível de $7,5 \%$ e variando o nível de lactose de 7 até $23 \%$ nos primeiros 14 dias após o desmame, encontraram um efeito linear no ganho de peso e consumo de ração, semelhante ao encontrado por GATNAU \& ZIMMERMAN (1990).

ERMER et al. (1992) conduziram um experimento para verificar a preferência de dietas, contendo leite desnatado ou plasma, e verificaram que os leitões desmamados preferiam as dietas com plasma, e que a preferência se iniciava no segundo dia (60\% dos animais), aumentando até o vigésimo primeiro dia ( $84 \%$ dos animais). Tal preferência, também foi constatada em ratos por THOMPSON et al.(1993).

RUSSEL (1994) conduziu três experimentos para avaliar o efeito das fontes de plasma (bovino ou suíno), e o método de processamento (plasma AP 820; plasma com nivel baixo de mineral, AP 920; ou plasma desfibrinado com baixo mineral, AP 920df), no crescimento de leitões após o desmame. Utilizando dietas com 7,5\% de inclusão de plasma, não encontraram diferenças entre as fontes, 
bem como no processamento, concluindo que as frações de minerais e fibrina, não contribuem na promoção do crescimento.

Da mesma maneira, GATNAU \& ZIMMERMAN (1994) testaram o plasma bovino e suíno, com remoção ou não da fração mineral, em dois experimentos. No primeiro, a resposta ao plasma bovino foi superior ao plasma suíno, e no segundo experimento, o plasma suino superou os resultados de performance obtidos com o plasma bovino. Estas diferenças poderiam estar relacionadas às grandes diferenças nas taxas de crescimento observadas nos primeiros 14 dias pós-desmame entre os experimentos. Além destes fatores existem as diferenças entre processamentos e/ou temperatura, que podem influenciar grandemente a performance animal (WAIBEL ${ }^{1}$ et al., 1977; citado por HANSEN et al., 1993).

\subsection{Modo de ação do plasma}

As proteinas do plasma têm sido estudadas intensivamente nos últimos anos, porém não se sabe ao certo os mecanismos específicos do modo de ação. Observa-se que quanto maior o desafio ambiental, mais consistente parece ser a resposta positiva da inclusão do plasma.

\footnotetext{
'WAIBEL, P.E.; CUPERLOVIC, M.; HURRELL, R.F.; CARPENTER, K.J. Processing damage to lysine and other amino acids in the manufacture of blood meal. J. Agric. Food Chem., 25:171., 1977.
} 
GATNAU \& ZIMMERMAN (1991b) conduziram dois experimentos com leitões, em ambientes diferentes, onde um consistia no esquema "all-in-all-out" e o outro um fluxo contínuo de alojamento. Observaram que não houve diferença para os parâmetros de ganho de peso, eficiência alimentar, e "score" de fezes no ambiente "all-in-all-out". Somente foi observado um maior consumo de ração para dieta com plasma. Já no segundo experimento, com fluxo contínuo de alojamento, encontraram aumento no ganho de peso, consumo de ração e menor incidencia de diarréia nos animais tratados com plasma.

Devido às diferenças encontradas quanto aos níveis ideais de inclusão de plasma, bem como da magnitude dos ambientes onde vários experimentos foram conduzidos, COFFEY \& CROMWELL (1995) realizaram uma série de três experimentos para verificar a taxa de inclusão de plasma nas dietas e a resposta quanto ao ambiente, na presença ou não de agentes antimicrobianos. Estes autores não conseguiram detectar diferenças no ganho de peso, nem no consumo de ração entre os tratamentos, quando um experimento foi conduzido em instalações limpas e controladas. Porém, quando outro experimento foi conduzido em instalações convencionais, houve resposta no ganho de peso e consumo de ração, mostrando haver interação com o ambiente. Também a adição de agentes antimicrobianos proporcionou resposta positiva na performance e consumo de ração, quando comparada com dietas sem agentes antimicrobianos, com ou sem a adição de plasma, mostrando ser as respostas independentes. 
TOUCHETTE et al. (1996) conduziram dois experimentos para verificar os efeitos do plasma, lactose e da proteina de soja na performance de leitões desmamados entre 17 e 20 dias de idade, em dois ambientes (creche em local isolado ou não). Verificaram que houve uma interação entre plasma e lactose na dieta, bem como a resposta do plasma foi dependente do sistema de manejo utilizado, não encontrando resposta à adição de plasma no ambiente isolado.

Uma das possíveis razões para as melhores performances encontradas em alguns experimentos onde foi fornecido o plasma, é a presença de proteinas plasmáticas biologicamente ativas, as imunoglobulinas presentes no plasma desidratado, às quais têm sido atribuído por alguns autores como contribuintes da imunocompetência de leitões jovens (GATNAU ${ }^{2}$ et al., 1989, citados por HANSEN et al., 1993). Entretanto, estas proteinas sofrem desnaturação à temperaturas entre 56 a $60^{\circ} \mathrm{C}$, bem abaixo da temperatura usada no processamento de "spray dry". Apesar disso, estas imunoglobulinas podem manter algum grau de especificidade e ligar a bactérias intraluminarmente, prevenindo assim a secreção de enterotoxinas (HANSEN et al., 1993).

CAIN (1995) relatou um estudo, onde se utilizaram as frações da proteína contida no plasma (albumina, imunoglobulinas e proteinas de baixo peso molecular), na mesma proporção encontrada no produto integral ao nível de $8 \%$ de inclusão, em dietas isolisínicas e isometioninicas, sem antibióticos e sem farelo de soja, em ambiente não lavado e não desinfetado, e encontrou resultados de

\footnotetext{
${ }^{2}$ GATNAU, R.; PAUL, P.S.; ZIMMERMAN, D.R. Spray dried plasma as a source of immunoglobulins for newborn piglets. J. Anim. Sci., 67(Suppl. 1):244 (Abstr)., 1989.
} 
performance semelhantes para as dietas que continham plasma e frações de imunoglobulinas, as quais foram superiores às demais dietas. Também encontrou uma maior atividade de lactase e maltase nos animais tratados com plasma e imunoglobulinas.

RODAS et al.(1995) conduziram um experimento para verificar o efeito de alto nível de inclusão de plasma, sobre a performance e os níveis de IGF-I, GH, insulina e concentração de glucose no plasma de leitões desmamados precocemente, e encontraram melhora no ganho de peso e consumo de ração na primeira semana pós-desmame e aumento no consumo de ração na segunda semana pós-desmame, substituindo a proteína do farelo de soja pela proteína do plasma. Não foi encontrado diferença na concentração de IGF-I e glucose no plasma dos leitões, porém a concentração de GH foi aumentada e a concentração de insulina foi diminuida pela adição do plasma desidratado na dieta durante o período experimental de 28 dias, indicando que a substituição da proteína do farelo de soja pela de plasma na dieta altera a concentração de hormônios, porém a relação entre o "status" nutricional e o sistema endócrino não está bem clara, necessitando ainda de novos estudos.

Com a finalidade de verificar a resposta de leitões às frações protéicas do plasma, WEAVER et al.(1995) testaram a inclusão de $8 \%$ de plasma, $2 \%$ de proteínas de baixo peso molecular, $4,6 \%$ de albumina e $2,7 \%$ de imunoglobulina frente à uma dieta basal sem plasma. Encontraram que a adição de plasma, albumina ou imunoglobulina melhorou a performance e o consumo de ração, 
comparado com o controle e que a adição da fração de baixo peso molecular resultou em pior performance.

Da mesma maneira, OWEN et al.(1995b) encontraram uma resposta positiva à adição de imunoglobulina ou albumina na performance de leitões de 0 a 21 , e 0 a 35 dias pós-desmame. Porém a resposta à adição de albumina num experimento prévio no período de 0 a 14 dias pós-desmame não foi observada pelos autores, os quais sugeriram mais pesquisas nessa área.

PIERCE et al.(1995), trabalhando com a adição de imunoglobulina, albumina e fração de baixo peso molecular ao mesmo nivel encontrado numa dieta com $8 \%$ de plasma, verificaram resposta positiva somente para imunoglobulina. Num segundo experimento, variando a adição de imunoglobulina na dieta em $40 \%$, $80 \%$ e $120 \%$ do nivel encontrado com a adição de $8 \%$ de plasma, verificaram que o nivel intermediário maximizou a resposta na primeira semana experimental, concluindo que o efeito benéfico do plasma estava associado à fração de imunoglobulina presente. 


\section{MATERIAL E MÉTODOS}

O experimento foi conduzido nas instalações de creche do Setor de Suinocultura do Departamento de Zootecnia, da Escola Superior de Agricultura "Luiz de Queiroz", Universidade de São Paulo, em Piracicaba-SP, no período de dezembro de 1996 a janeiro de 1997.

A creche possuia 20 gaiolas metálicas suspensas, com piso semi-ripado, medindo $1,50 \mathrm{~m}$ de largura por $1,20 \mathrm{~m}$ de comprimento, equipadas com comedouros semi-automáticos, bebedouros tipo "chupeta", e lâmpadas infra-vermelhas de 250 Watts. Antes do alojamento dos animais a creche foi limpa e desinfetada, permanecendo vazia por um período aproximado de 90 dias. Neste ambiente de experimentação foram observadas as temperaturas mínima e máxima diariamente, conforme a Figura 2.

Foram utilizados 120 leitões, provenientes da Fazenda Água Branca em Indaiatuba-SP, sendo machos castrados e fêmeas, obtidos através do cruzamento de fêmeas Agroceres com machos 
terminadores Dalland, desmamados aos 21 dias de idade média com peso médio de $5,75 \mathrm{~kg}$.

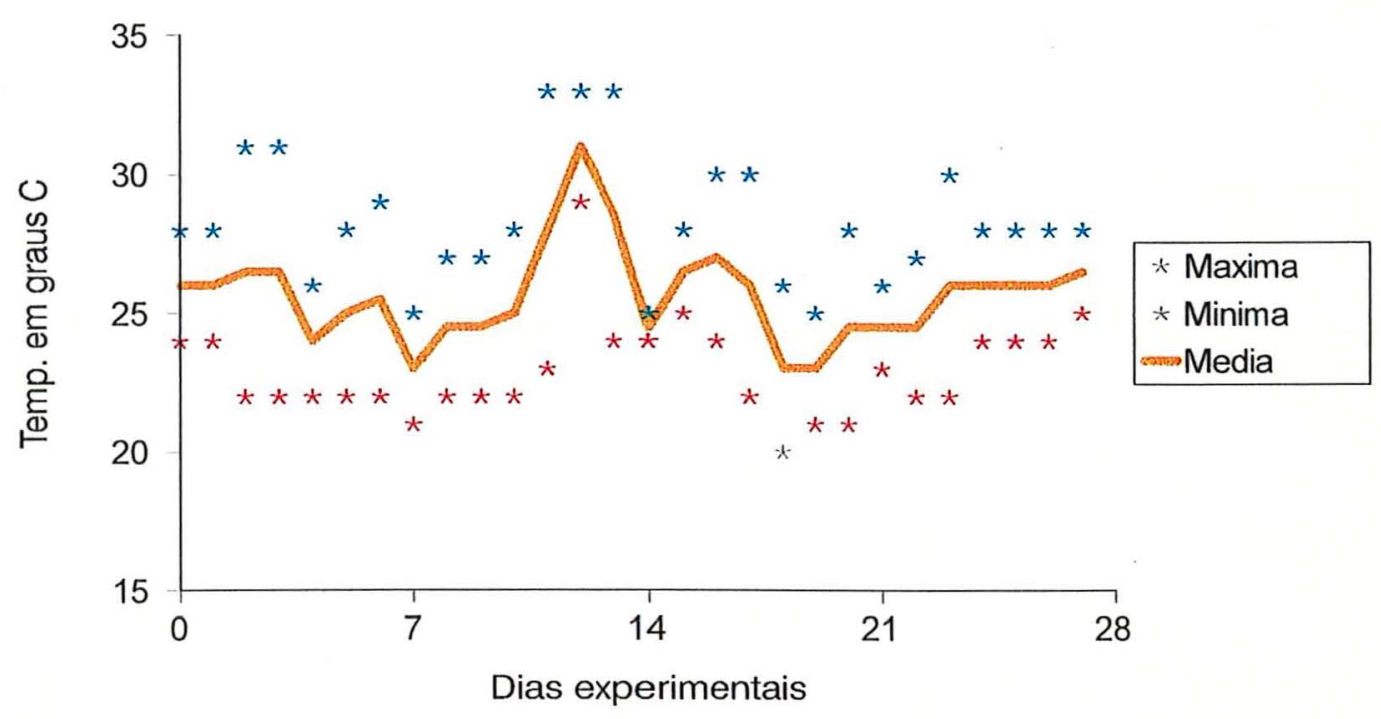

Figura 2. Dados de temperatura observados durante o período experimental.

A composição química e conteúdo energético dos ingredientes utilizados estão listados na Tabela 1, e a composição em aminoácidos está listada na Tabela 2. A composição percentual das rações experimentais, bem como os nutrientes calculados de cada uma delas estão apresentados nas Tabelas 3, 4, 5 e 6. As dietas foram formuladas para atingir o mínimo ou exceder os níveis recomendados pelo NRC (1988) e Rostagno et al. (1983). 
Ração farelada e água foram fornecidos à vontade durante todo o período experimental que foi de 28 dias, sendo o primeiro dia experimental considerado como dia zero.

O período experimental consistiu de duas fases, sendo a Fase I de 0 a 14 dias e a Fase II de 14 a 28 dias de experimentação. Os tratamentos na Fase I eram quatro dietas, com inclusão de níveis crescentes de $0,2,5,5,0$ e $7,5 \%$ de plasma de suínos desidratado por "Spray Dryer". Na Fase II, os tratamentos consistiam em duas dietas, sendo o nível zero o controle e a dieta teste com $2,5 \%$ de inclusão de plasma e $2,5 \%$ de inclusão de hemácias, para se testar os efeitos dos níveis crescentes de inclusão de plasma na primeira fase sobre os efeitos na performance na segunda fase.

Nas duas fases de experimentação, as dietas dos tratamentos, foram formuladas para conter os mesmos niveis dos aminoácidos, metionina, lisina, treonina e triptofano, bem como os mesmos níveis de lactose. O sal foi adicionado às dietas, procurando-se manter semelhante os niveis de cloro, conforme demonstrado nas Tabelas $3,4,5$ e 6 . 


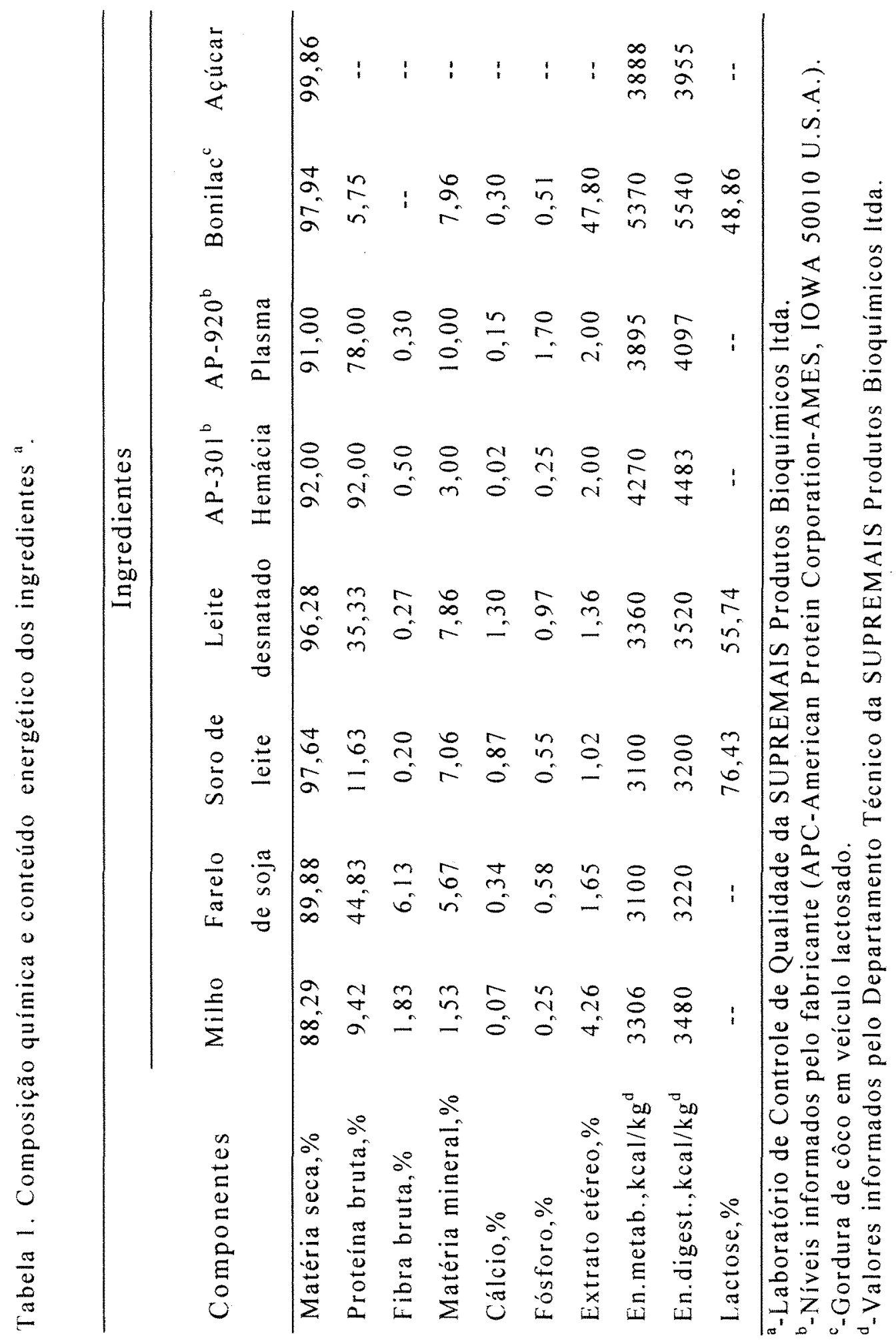


Tabela 2. Composição em aminoácidos dos ingredientes ${ }^{a}$.

\begin{tabular}{lccccccc}
\hline Aminoácidos & Milho & Farelo & Sorode & Leite & Bonilac & AP-301 & AP-920 \\
\multicolumn{1}{c}{$(\%)$} & & de soja & leite & desnatado & & Hemácia & Plasma \\
\hline Arginina & 0,484 & 3,143 & 0,292 & 0,997 & 0,120 & 4,000 & 4,500 \\
Histidina & 0,251 & 1,149 & 0,228 & 0,908 & 0,100 & 7,500 & 2,500 \\
Isoleucina & 0,287 & 2,141 & 0,673 & 1,696 & 0,280 & 0,600 & 2,000 \\
Leucina & 1,033 & 3,596 & 1,165 & 3,348 & 0,480 & 13,400 & 7,400 \\
Lisina & 0,277 & 2,716 & 1,000 & 2,610 & 0,420 & 9,000 & 6,900 \\
Metionina & 0,181 & 0,639 & 0,209 & 0,731 & 0,130 & 0,800 & 0,700 \\
Fenilalanina & 0,390 & 2,336 & 0,391 & 1,432 & 0,210 & 7,100 & 4,800 \\
Treonina & 0,318 & 1,776 & 0,775 & 1,473 & 0,330 & 3,600 & 4,300 \\
Triptofano & 0,049 & 0,534 & 0,273 & 0,432 & 0,080 & 1,200 & 1,300 \\
Valina & 0,425 & 2,655 & 0,665 & 2,022 & 0,310 & 9,200 & 5,200 \\
Cistina & 0,189 & 0,671 & 0,225 & 0,290 & 0,130 & 0,600 & 1,800 \\
Gicina & 0,347 & 1,983 & 0,219 & 0,656 & 0,270 & 4,700 & 2,600 \\
\hline
\end{tabular}

-Laboratório de Controle de Qualidade da SUPREMAIS Produtos Bioquímicos ltda.

${ }^{b}$-Níveis informados pelo fabricante - APC - American Protein Corporation - AMES. IOWA U.S.A.

-Gordura de côco em veículo lactosado. 
Tabela 3. Composição percentual das rações experimentais - Fase I

\begin{tabular}{|c|c|c|c|c|}
\hline \multirow[b]{2}{*}{ Ingredientes } & \multicolumn{4}{|c|}{ Níveis de inclusão de plasma, $\%$} \\
\hline & 0 & 2,5 & 5,0 & 7,5 \\
\hline Açúcar & 1,818 & 1,818 & 1,818 & 1,818 \\
\hline Milho moido & 49,018 & 47,822 & 46,451 & 45,236 \\
\hline Farelo de soja & 20,000 & 20,000 & 20,000 & 20,000 \\
\hline Plasma & -- & 2,500 & 5,000 & 7,500 \\
\hline Leite desnatado & 11.591 & 7,727 & 3,864 & -- \\
\hline Soro de leite & 8.636 & 11,364 & 14,318 & 17,045 \\
\hline Bonilac ${ }^{b}$ & 5.000 & 5,000 & 5,000 & 5,000 \\
\hline DL-Metionina $98 \%$ & 0.227 & 0,232 & 0,241 & 0,246 \\
\hline L-Lisina $\mathrm{HCl} 98 \%$ & 0,386 & 0,273 & 0,136 & 0,023 \\
\hline L-Treonina $98 \%$ & 0,182 & 0,100 & 0,032 & $\cdots$ \\
\hline L-Triptofano $96 \%$ & 0,055 & 0,032 & 0,009 & -- \\
\hline Calcário $38 \%$ & 0.773 & 0,909 & 1,045 & 1,136 \\
\hline Fosfato bicálcico & 1.273 & 1,182 & 1,045 & 0,955 \\
\hline Sal $(\mathrm{NaCl})$ & 0.273 & 0,273 & 0,273 & 0,273 \\
\hline $\mathrm{CuSO}_{4} \mathrm{H}_{2} \mathrm{O}(35 \%)$ & 0,070 & 0,070 & 0,070 & 0,070 \\
\hline $\mathrm{ZnO} 76 \%$ & 0.318 & 0,318 & 0,318 & 0,318 \\
\hline Olaquindox $98 \%$ & 0,010 & 0,010 & 0,010 & 0,010 \\
\hline Tylan S $100^{\circ}$ & 0,100 & 0,100 & 0,100 & 0,100 \\
\hline Antioxidante (B.H.T.) & 0.020 & 0,020 & 0,020 & 0,020 \\
\hline Premix vitamínico ${ }^{d}$ & 0,150 & 0,150 & 0,150 & 0,150 \\
\hline Premix mineral ${ }^{*}$ & 0,100 & 0,100 & 0,100 & 0,100 \\
\hline Total & 100,000 & 100,000 & 100,000 & 100,000 \\
\hline
\end{tabular}

a-APC 920; American Protein Corporation, AMES IA.

${ }^{b}$-Gordura de côco em veículo lactosado.

'-Suprindo $100 \mathrm{mg}$ de Tilosina, $100 \mathrm{mg}$ Sulfametazina por $\mathrm{kg}$ de ração.

${ }^{\mathrm{d}}$-Suprindo as seguintes quantidades por $\mathrm{kg}$ de ração: Vit. A, $12000 \mathrm{UI}$; Vit. $\mathrm{D}_{3}, 2250$ UI; Vit.E, $27 \mathrm{mg}$; Vit.K $3.3 \mathrm{mg}$; Tiamina, 2,25 mg; Riboflavina, $6 \mathrm{mg}$; Piridoxina, $2,25 \mathrm{mg}$; Cianocobalamina, $27 \mathrm{mcg}$; Ác. Fólico, $400 \mathrm{mcg}$; Biotina, $150 \mathrm{mcg}$, Ác.Pantotênico, $22,5 \mathrm{mg}$; Niacina, $45 \mathrm{mg}$; Selênio, $300 \mathrm{mcg}$

'-Suprindo as seguintes quantidades por $\mathrm{kg}$ de ração: Ferro, $88 \mathrm{mg}$; Cobre, $15 \mathrm{mg}$; Zinco, $80 \mathrm{mg}$; Mangânes, $45 \mathrm{mg}$; Iodo, $1 \mathrm{mg}$ 
Tabela 4. Composição percentual das rações experimentais - Fase II.

\begin{tabular}{|c|c|c|}
\hline \multirow{3}{*}{ Ingredientes } & \multicolumn{2}{|c|}{ Dietas } \\
\hline & Controle & $2,5 \%$ plasma \\
\hline & & $2,5 \%$ hemácias \\
\hline Açúcar & 2,000 & 2,000 \\
\hline Milho moído & 51,155 & 57,185 \\
\hline Farelo de soja & 30,500 & 20,000 \\
\hline Hemácias ${ }^{a}$ & - & 2,500 \\
\hline Plasma ${ }^{b}$ & -- & 2,500 \\
\hline Óleo vegetal & 1,500 & 1,000 \\
\hline Soro de leite & 9,750 & 9,750 \\
\hline Bonilac ${ }^{\circ}$ & 1,650 & 1,650 \\
\hline DI-Metionina $98 \%$ & 0,115 & 0,135 \\
\hline L-Lisina $\mathrm{HCl} 98 \%$ & 0,175 & -- \\
\hline L-Treonina $98 \%$ & 0,025 & -- \\
\hline Calcário $38 \%$ & 0,850 & 1,200 \\
\hline Fosfato bicálcico & 1,550 & 1,400 \\
\hline Sal $(\mathrm{NaCl})$ & 0,300 & 0,250 \\
\hline $\mathrm{CuSO}_{4} \mathrm{H}_{2} \mathrm{O}(35 \%)$ & 0,070 & 0,070 \\
\hline Olaquindox $98 \%$ & 0,010 & 0,010 \\
\hline Tylan S100d & 0,100 & 0,100 \\
\hline Premix vitamínico ${ }^{e}$ & 0,150 & 0,150 \\
\hline Premix mineral ${ }^{f}$ & 0,100 & 0,100 \\
\hline TOTAL & 100,000 & 100,000 \\
\hline
\end{tabular}

${ }^{a}$-AP 301; American Protein Corporation, AMES IA.

b-AP 920; American Protein Corporation, AMES IA.

c-Gordura de côco em veículo lactosado.

d-Suprindo $100 \mathrm{mg}$ de Tilosina, $100 \mathrm{mg} \mathrm{Sulfametazina} \mathrm{por} \mathrm{kg} \mathrm{de} \mathrm{ração.}$

${ }^{-}$-Suprindo as seguintes quantidades por $\mathrm{kg}$ de ração: Vit.A, $12000 \mathrm{UI}$; Vt.D, 2250 UI; Vit.E, $27 \mathrm{mg}$; Vit. $\mathrm{K}_{3}, 3 \mathrm{mg}$; Tiamina, 2.25 mg; Riboflavina, $6 \mathrm{mg}$; Piridoxina, $2,25 \mathrm{mg}$; Cianocobalamina, $27 \mathrm{mcg}$; Ác.Fólico, $400 \mathrm{mcg}$; Biotina. $150 \mathrm{mcg}$, Ác.Pantotênico, $22.5 \mathrm{mg}$; Niacina, $45 \mathrm{mg}$; Selênio, $300 \mathrm{mcg}$

f-Suprindo as seguintes quantidades por kg de ração: Ferro, $88 \mathrm{mg}$; Cobre, $15 \mathrm{mg}$; Zinco, $80 \mathrm{mg}$; Mangânes, $45 \mathrm{mg}$; Iodo, $1 \mathrm{mg}$ 
Tabela 5. Nutrientes calculados das rações experimentais - Fase I.

\begin{tabular}{lcccc}
\hline \multicolumn{1}{c}{ Nutrientes } & \multicolumn{3}{c}{ Níveis de plasma desidratado na ração, \% } \\
\cline { 2 - 5 } & 0 & 2,5 & 5,0 & 7,5 \\
\hline Umidade, \% & 8,502 & 8,585 & 8,580 & 8,574 \\
En.digest.,kcal/kg & 3400 & 3403 & 3407 & 3412 \\
En.metabol.,kcal/kg & 3282 & 3287 & 3293 & 3300 \\
Proteina bruta, \% & 19,683 & 20,138 & 20,592 & 21,094 \\
Fibrabruta, \% & 2,185 & 2,165 & 2,143 & 2,124 \\
Extrato etéreo, \% & 5,091 & 5,091 & 5,086 & 5,085 \\
Matéria mineral, \% & 5,665 & 5,770 & 5,851 & 5,929 \\
Cálcio, \% & 0,952 & 0,958 & 0,956 & 0,945 \\
Fósforo, \% & 0,648 & 0,648 & 0,642 & 0,643 \\
Sódio, \% & 0,292 & 0,365 & 0,440 & 0,512 \\
Cloro, \% & 0,560 & 0,571 & 0,581 & 0,592 \\
Potássio, \% & 0,886 & 0,853 & 0,822 & 0,789 \\
Arginina, \% & 1,013 & 1,089 & 1,165 & 1,241 \\
Histidina, \% & 0,482 & 0,513 & 0,543 & 0,574 \\
Isoleucina, \% & 0,840 & 0,840 & 0,840 & 0,840 \\
Leucina, \% & 1,741 & 1,816 & 1,892 & 1,967 \\
Lisina, \% & 1,400 & 1,400 & 1,392 & 1,398 \\
Metionina, \% & 0,546 & 0,544 & 0,546 & 0,543 \\
Fenilalanina,\% & 0,867 & 0,937 & 1,008 & 1,078 \\
Treonina, \% & 0,943 & 0,931 & 0,933 & 0,969 \\
Triptofano, \% & 0,260 & 0,260 & 0,262 & 0,276 \\
Valina, \% & 1,053 & 1,118 & 1,183 & 1,248 \\
Met + Cist, \% & 0,832 & 0,867 & 0,907 & 0,942 \\
Lactose, \% & 14,893 & 14,998 & 14,929 \\
\hline & & & & \\
\hline
\end{tabular}


Tabela 6. Nutrientes calculados das rações experimentais - Fase II.

\begin{tabular}{|c|c|c|}
\hline \multirow{3}{*}{ Nutrientes } & \multicolumn{2}{|c|}{ Dietas } \\
\hline & Controle & $2,5 \%$ plasma \\
\hline & & $2,5 \%$ hemácias \\
\hline Umidade, $\%$ & 9,388 & 9,416 \\
\hline En.digestível, $\mathrm{kcal} / \mathrm{kg}$ & 3360 & 3440 \\
\hline En.metabol.,kcal/kg & 3272 & 3327 \\
\hline Proteína bruta $\%$ & 19,500 & 19,255 \\
\hline Fibra bruta, \% & 2.843 & 2,312 \\
\hline Extrato etéreo, \% & 5,232 & 5,407 \\
\hline Matéria mineral. $\%$ & 5,605 & 5,378 \\
\hline Cálcio, \% & 1,000 & 1,000 \\
\hline Fósforo, \% & 0,639 & 0,609 \\
\hline Sódio, \% & 0,235 & 0,305 \\
\hline Cloro, \% & 0,400 & 0,400 \\
\hline Potássio, \% & 0,849 & 0,670 \\
\hline Arginina, $\%$ & 1,240 & 1,143 \\
\hline Histidina, $\%$ & 0,504 & 0,645 \\
\hline Isoleucina, \% & 0,873 & 0,726 \\
\hline Leucina, $\%$ & 1,750 & 1,944 \\
\hline Lisina, \% & 1,200 & 1,200 \\
\hline Metionina, \% & 0,420 & 0,421 \\
\hline Fenilalanina, $\%$ & 0,956 & 1,024 \\
\hline Treonina, $\%$ & 0,812 & 0,814 \\
\hline Triptofano, \% & 0,216 & 0,226 \\
\hline Valina, $\%$ & 1,100 & 1,199 \\
\hline Met + Cist, $\%$ & 0,746 & 0,746 \\
\hline Lactose, $\%$ & 8,020 & 8,020 \\
\hline
\end{tabular}


A coleta de dados foi feita a cada 7 dias, com pesagem dos animais e da sobra das rações de cada unidade experimental para cálculo do consumo médio e conversão alimentar em cada período.

Foi utilizado o delineamento experimental em blocos casualizados, com 5 repetições de 6 animais em cada unidade experimental, distribuidos nos tratamentos de acordo com a raça, sexo e peso vivo inicial. Os dados de performance foram submetidos à análise de variância PROC GLM (General Linear Model) do SAS (Statistical Analysis System, 1985). Os graus de liberdade do fator nível de plasma na ração, foram decompostos em seus componentes individuais de regressão, através dos polinômios ortogonais. 


\section{RESULTADOS E DISCUSSÃO}

As médias das características de performance dos leitões, representadas pelo ganho diário de peso (GDP), conversão alimentar (CA) e consumo diário de ração (CDR), estão apresentadas nas Tabelas 7 e 8 , e Figuras $3,4,5,6,7,8,9$ e 10 . Os valores originais dos dados de performance, em função do nivel de inclusão de plasma na dieta, se encontram nas Tabelas A1, A2, A3, A4, A5, A6, A7 e A8 do Apêndice. 
Tabela 7. Média das caracteristicas de performance dos leitões em recria alimentados com rações contendo níveis crescentes de inclusão de plasma.

\begin{tabular}{|c|c|c|c|c|c|c|c|}
\hline \multirow[b]{2}{*}{ Item ${ }^{a}$} & \multirow[b]{2}{*}{ Sem. } & \multicolumn{6}{|c|}{ Níveis de inclusão de plasma, \% } \\
\hline & & 0 & 2,5 & 5,0 & 7,5 & $\mathrm{CV}^{6}, \%$ & $\mathrm{P}={ }^{\mathrm{c}}$ \\
\hline $\mathrm{N}^{\circ}$ de animais & & 30 & 30 & 30 & 30 & & \\
\hline $\mathrm{PMI}, \mathrm{kg}$ & & 5,76 & 5,74 & 5,75 & 5,76 & 0,65 & 0,8291 \\
\hline$\underline{P M F} \approx \underline{\mathrm{kg}}$ & & 18,53 & 19,52 & 19,42 & 19.30 & $\underline{5,08}$ & 0,3939 \\
\hline \multirow{8}{*}{ GDP, $\mathrm{g}$} & 1 & 214 & 249 & 263 & 264 & 19,57 & 0,3657 \\
\hline & 2 & 411 & 439 & 456 & 449 & 10.74 & 0,4770 \\
\hline & 3 & 548 & 581 & 547 & 537 & 9,25 & 0,5641 \\
\hline & 4 & 652 & 700 & 686 & 685 & 8,77 & 0,6298 \\
\hline & 1 a 2 & 313 & 344 & 360 & 356 & 12,11 & 0,3083 \\
\hline & 1 a 3 & 391 & 423 & 422 & 417 & 7,79 & 0,3882 \\
\hline & $1 \mathrm{a} 4$ & 456 & 492 & 488 & 484 & 7,29 & 0,3911 \\
\hline & 2 a 4 & 600 & 641 & 617 & $6 \underline{1} 1$ & 7,49 & 0.5705 \\
\hline \multirow{8}{*}{ CDR, $\mathrm{g}$} & 1 & 246 & 278 & 263 & 313 & 16.07 & 0,1523 \\
\hline & 2 & 595 & 639 & 664 & 700 & 10,23 & 0,1390 \\
\hline & 3 & 1006 & 1063 & 1060 & 1082 & 5,73 & 0,2727 \\
\hline & 4 & 1046 & 1128 & 1151 & 1126 & 5,89 & 0,1111 \\
\hline & 1 a 2 & 420 & 458 & 463 & 507 & 11,14 & 0,1237 \\
\hline & 1 a 3 & 616 & 660 & 662 & 698 & 7,46 & 0,1207 \\
\hline & 1 a 4 & 723 & 777 & 784 & 805 & 6,62 & 0,1244 \\
\hline & $2 \mathrm{a} 4$ & 1026 & 1096 & 1106 & 1104 & 5,38 & 0,1471 \\
\hline \multirow{8}{*}{$\mathrm{CA}$} & 1 & 1,17 & 1,13 & 1,05 & 1,15 & 14,41 & 0,6756 \\
\hline & 2 & 1,47 & 1,46 & 1,47 & 1,53 & 7,56 & 0,7752 \\
\hline & 3 & 1,84 & 1,83 & 1,99 & 1,98 & 8,81 & 0,3387 \\
\hline & 4 & 1,61 & 1,61 & 1,71 & 1,65 & 4,88 & 0,2287 \\
\hline & 1 a 2 & 1,35 & 1,33 & 1,32 & 1,38 & 6,19 & 0,6683 \\
\hline & 1 a 3 & 1,57 & 1,56 & 1,61 & 1,63 & 3,61 & 0,2320 \\
\hline & 1 a 4 & 1,59 & 1,58 & 1,64 & 1,64 & 3,07 & 0,1831 \\
\hline & 2 a 4 & 1,71 & 1,71 & 1.83 & 1,79 & 5,49 & 0,1918 \\
\hline
\end{tabular}

a - PMI = peso médio inicial, PMF $=$ peso médio final, GDP ganho diário de peso, CDR = consumo diário de ração e $\mathrm{CA}=$ conversão alimentar.

b - Coeficiente de variação.

- Probabilidade 


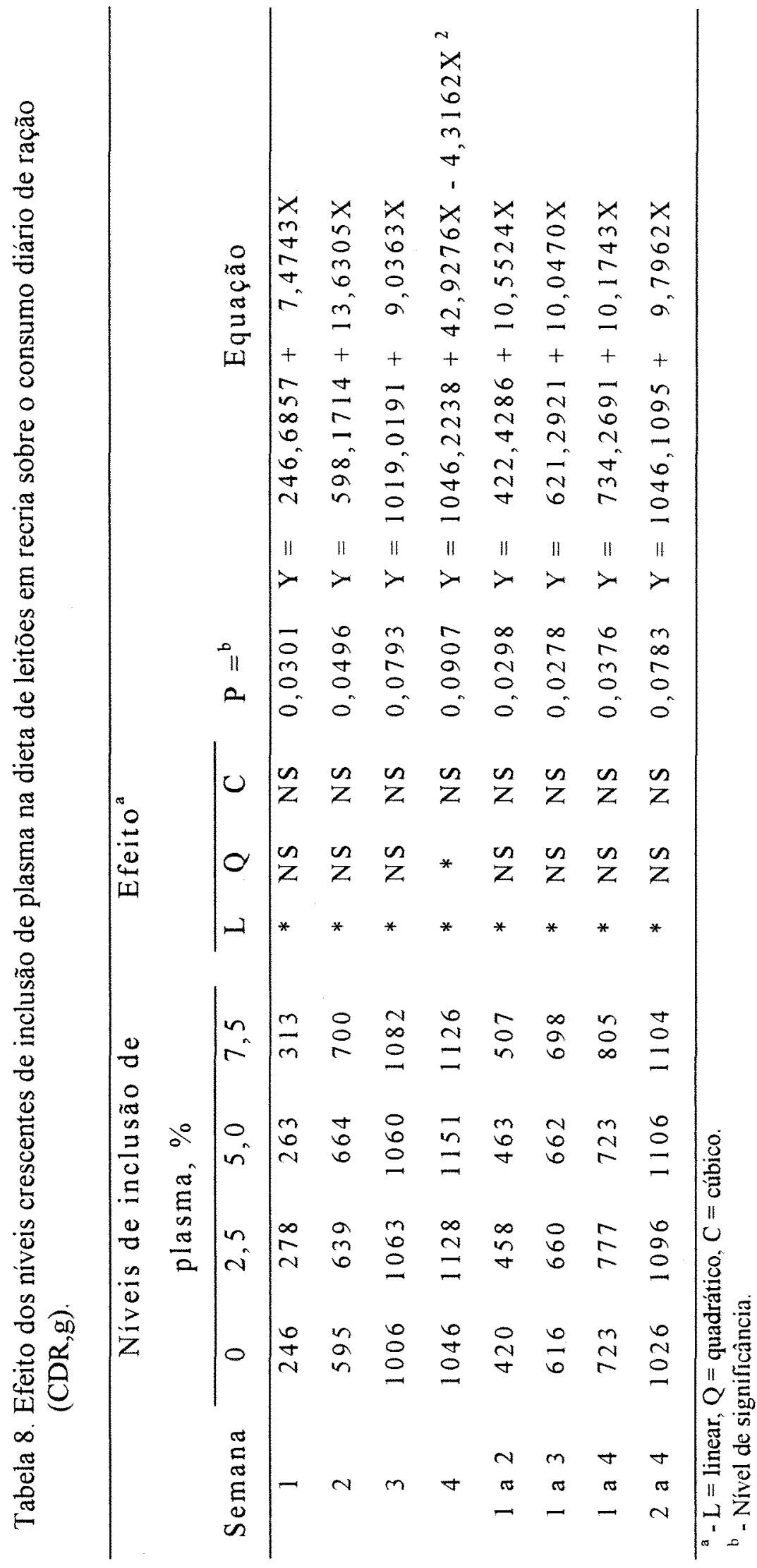


Durante a primeira semana do experimento, o nível de inclusão de plasma na dieta exerceu efeito linear no consumo diário de ração $(P=0,0301)$. A equação que descreve esta resposta é fornecida na Tabela 8 e ilustrada na Figura 3 . O ganho diário de peso e a conversão alimentar não foram influenciadas pelos tratamentos $(P>0,10)$, porém o ganho diário de peso foi $16,4 \%$, $22,9 \%$ e $23,4 \%$ superior ao controle para os níveis de inclusão de plasma de $2,5 \%, 5,0 \%$ e $7,5 \%$ respectivamente.

Nas duas primeiras semanas de experimentação, os niveis crescentes de inclusão de plasma na ração proporcionaram uma resposta linear no consumo diário de ração $(P=0,0298)$. A equação que descreve esta resposta é fornecida na Tabela 8 e ilustrada na Figura 7. Resultado semelhante foi encontrado por GATNAU \& ZIMMERMAN (1991b), e RODAS et al.(1995), que verificaram um contínuo aumento no consumo diário de ração na segunda semana do experimento, porém sem afetar o ganho diário de peso

O nível crescente de inclusão de plasma, na dieta da primeira fase ( 0 a 14 dias) proporcionou resposta linear positiva para o consumo diário de ração $(\mathrm{P}=0,0783)$ na terceira e quarta semana de experimentação (14 a 28 dias). A equação que descreve esta resposta é fornecida na Tabela 8 e ilustrada na Figura 10 . O ganho diário de peso e a conversão alimentar não foram influenciados pelos tratamentos $(P>0,10)$.

KATS et al.(1994b), verificaram aumento no ganho diário de peso e consumo diário de ração com níveis crescente de plasma na dieta de leitões até 14 dias, porém o ganho de peso foi reduzido no 
período de 14 a 28 dias após a retirada do plasma da dieta, sem no entanto afetar o consumo e a eficiência alimentar, ao contrário do encontrado neste trabalho, onde o ganho de peso e a conversão não foram afetados, porém o consumo foi crescente. Uma diferença entre o presente experimento e o experimento de KATS et al.(1994b) foi que a dieta da segunda fase possuía somente hemácias ao nivel de $2,5 \%$ podendo ter ocorrido uma diferença na palatabilidade.

Neste experimento, foi observado uma diferença numérica no padrão de consumo de ração quando os animais dos tratamentos com níveis de 5,0 e $7,5 \%$ de plasma, foram submetidos à dietas com $2,5 \%$ de plasma mais hemácias, sugerindo que estes sentiram mais a diferença na mudança das dietas do que aqueles do tratamento onde o nível de plasma na ração, foi constantemente $2,5 \%$.

A Figura 6, ilustra a diferença no padrão de ingestão de alimento, onde a resposta foi quadrática $(\mathrm{P}=0,0907)$ para o consumo de ração, considerando-se somente a última semana experimental.

Considerando o periodo total de experimentação, o nível de inclusão de plasma na dieta da primeira fase proporcionou resposta linear crescente $(\mathrm{P}=0,0376)$ para o consumo diário de ração. A equação que descreve esta resposta é fornecida na Tabela 8 e ilustrada na Figura 9. O ganho diário de peso e a conversão alimentar não foram influenciados pelos tratamentos $(\mathrm{P}>0,10)$. COFFEY et al.(1995) trabalharam com niveis de até $12 \%$ de plasma na dieta da fase I e não encontraram resposta no ganho de peso e no consumo de ração, somente na conversão alimentar. Quando os experimentos foram conduzidos na estação experimental, não 
encontravam resposta à adição do plasma, mas quando os experimentos foram conduzidos numa instalação convencional, houve resposta ao plasma.

A falta de resposta quanto ao de ganho de peso, aos níveis de plasma em nosso trabalho, pode ter ocorrido justamente por ser o ambiente menos contaminado ou com menor desafio em relação a uma instalação convencional, o que também foi observado por GATNAU \& ZIMMERMAN (1991b). Entretanto, conforme demonstrado na Tabela A9 do apêndice, onde estão listadas as médias de peso dos leitões dos blocos em cada período, observou-se uma tendência dos animais mais leves ao desmame, responderem com ganho de peso maior, do que aqueles mais pesados.

ERMER et al.(1992) mostraram a preferência dos leitões pela dietas contendo plasma comparado com a dieta contendo leite desnatado, onde o consumo foi superior em $200 \mathrm{grs} / \mathrm{dia}$. Resultado semelhante foi encontrado neste estudo e também por SOHN et al. (1991) e HANSEN et al.(1993). O mecanismo pelo qual o plasma proporciona um maior consumo de ração não é conhecido. No entanto, o uso do plasma nas dietas de leitões desmamados precocemente parece estimular um maior consumo de alimento através da melhoria da palatabilidade da dieta. 


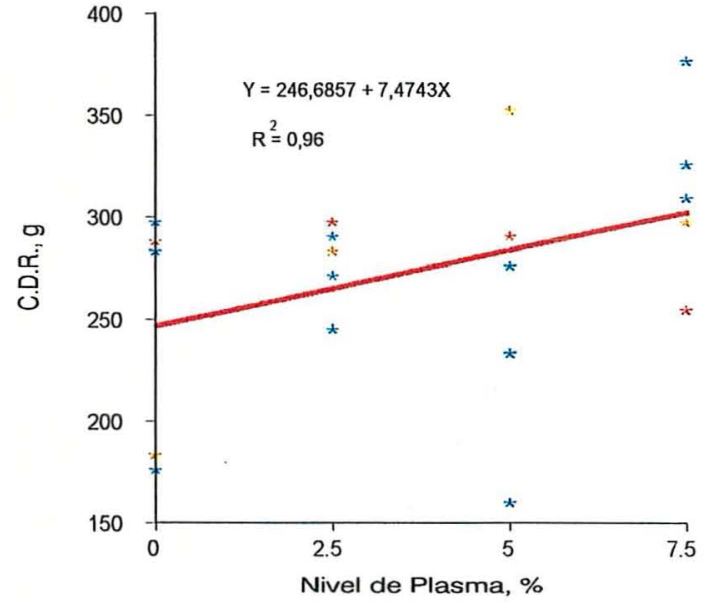

Figura 3. Efeito dos níveis de plasma sobre o consumo diário de ração $(\mathrm{CDR}, \mathrm{g})$ de leitões em recria na primeira semana de experimentação.

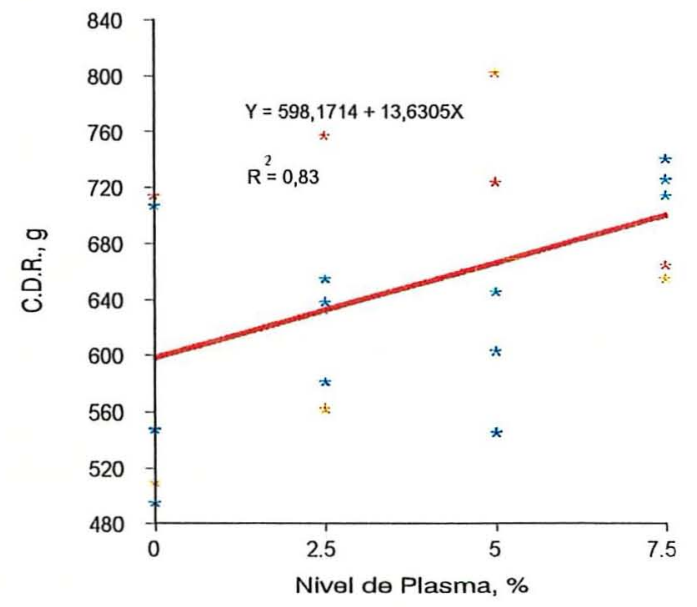

Figura 4. Efeito dos níveis de plasma sobre o consumo diário de ração $(\mathrm{CDR}, \mathrm{g})$ de leitões em recria na segunda semana de experimentação.

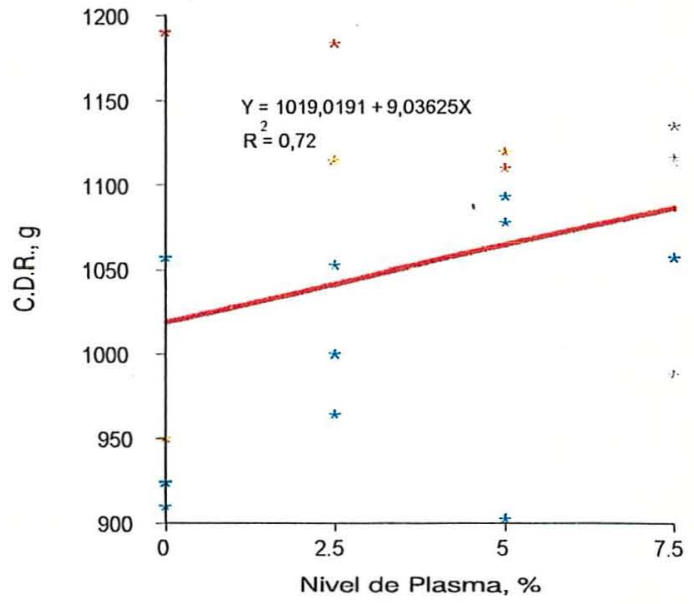

Figura 5. Efeito dos niveis de plasma sobre o consumo diário de ração $(\mathrm{CDR}, \mathrm{g})$ de leitões em recria na terceira semana de experimentação.

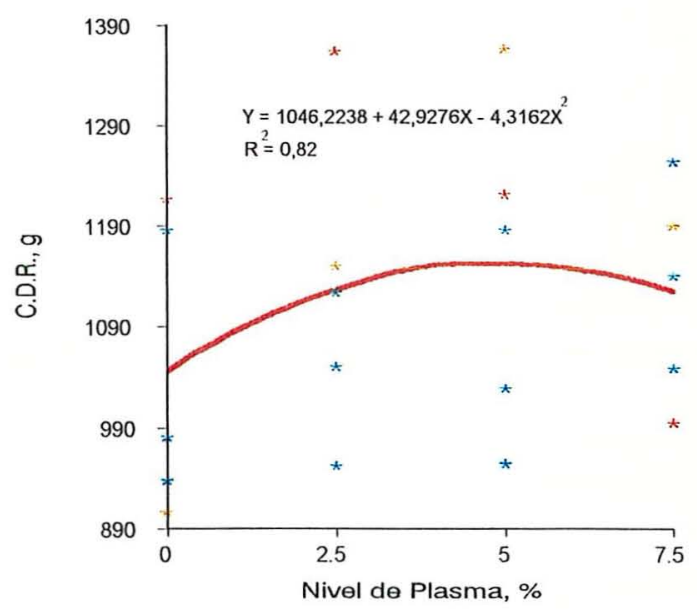

Figura 6. Efeito dos níveis de plasma sobre o consumo diário de ração $(\mathrm{CDR}, \mathrm{g})$ de leitões em recria na quarta semana de experimentação. 


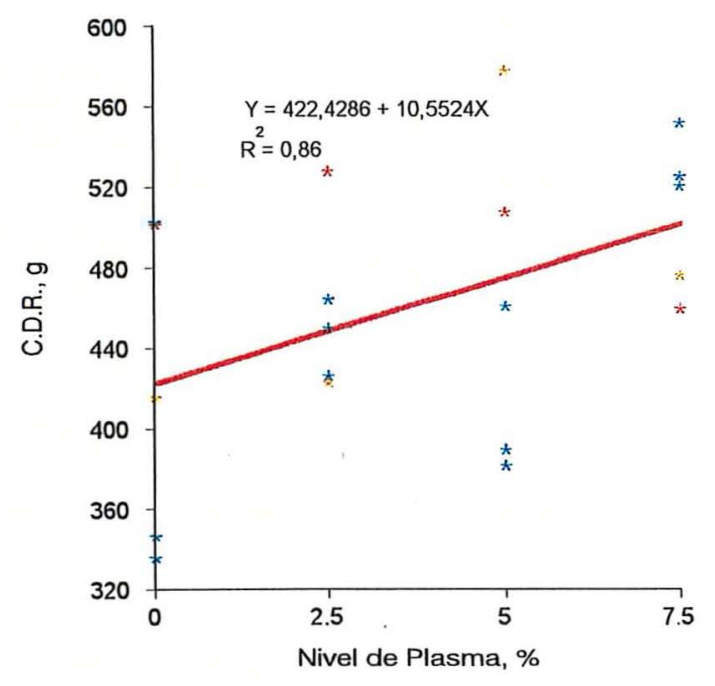

Figura 7. Efeito dos níveis de inclusão de plasma sobre o consumo diário de ração $(\mathrm{CDR}, \mathrm{g})$ de leitões em recria nas duas primeiras semanas de experimentação ( 0 a 14 dias).

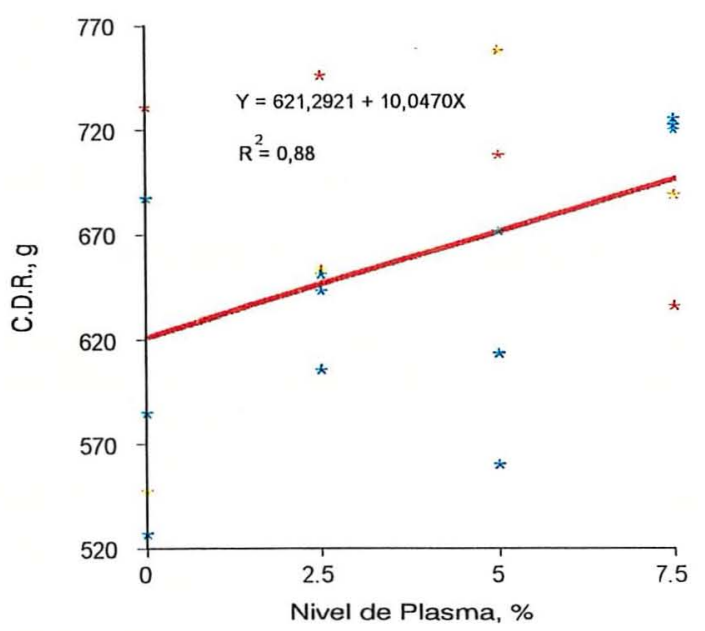

Figura 8. Efeito dos níveis de inclusão de plasma sobre o consumo diário de ração (CDR, g) de leitões em recria nas três primeiras semanas de experimentação ( 0 a 21 dias).

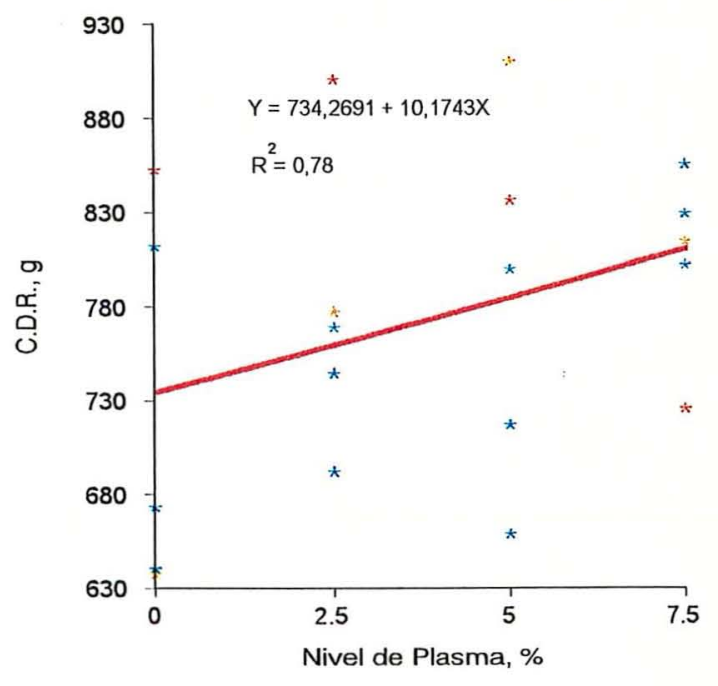

Figura 9. Efeito dos niveis de inclusão de plasma sobre o consumo diário de ração (CDR, g) de leitões em recria nas quatro semanas de experimentação ( () a 28 dias).

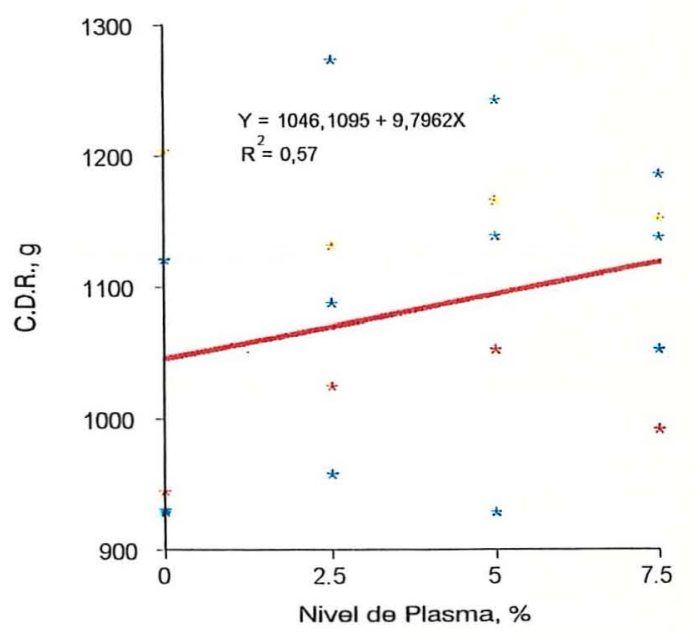

Figura10. Efeito dos níveis de inclusão de plasma sobre o consumo diário de ração $(\mathrm{CDR}, \mathrm{g})$ de leitões em recria na duas últimas semanas de experimentação (14 a 28 dias). 


\section{CONCLUSÕES}

Com base nos dados do presente trabalho, pode-se concluir que o plasma suíno desidratado por "spray dryer", até $7,5 \%$ na dieta de leitões desmamados aos 21 dias, proporcionou um aumento no consumo diário de ração, no período de 0 a 14 dias pós-desmama. Esse efeito no consumo diário de ração foi mantido no período de 14 a 28 dias pós-desmama quando uma combinação de $2,5 \%$ de plasma com $2,5 \%$ de hemácias foi utilizado na dieta. 


\section{REFERÊNCIAS BIBLIOGRÁFICAS}

AUGENSTEIN, M.L.; JOHNSTON, L.J.; SHURSON, G.C.; HAWTON, J.D.; PETTIGREW, J.E. Formulating FarmSpecific Swine Diets. Minnesota: Minnesota Extension Service, University of Minnesota. BU-6496-F, 1994. $21 \mathrm{p}$.

CAIN, C.M. Mode of action of spray-dried porcine plasma in weanling pigs. American Association of Swine Practitioners, 1995. p. 225-226.

COFFEY, R.D.; CROMWELL, G.L. The impact of environment and antimicrobial agents on the growth response of early-weaned pigs to spray-dried porcine plasma. Journal of Animal Science. v. 73, n.9, p.2532-2539, 1995.

ERMER, P.M.; MILlER, P.S.; LEWIS, A.J.; GIESEMANN, M.A. The preference of weanling pigs for diets containing either skimmed milk or spray-dried porcine plasma. Journal of Animal Science. v. 70, p. 60,1992 . Supplement, 1.

FRIESEN, K.G., NELSEN, R.D.; GOODBAND, K.C.; BEHNKE, K.C.; KATS, L.J. The effect of moist extrusion of soy products on growth performance and nutrient utilization in the earlyweaned Pig. Journal of Animal Science. v.71, n.9, p.20992109,1993 
GATNAU, R.; ZIMMERMAN, D.R. Spray dried porcine plasma (SDPP) as a source of protein for weanling pigs. Journal of Animal Science. v. 68, p. 374,1990 . Supplement, 1 .

GATNAU, R.; ZIMMERMAN, D.R.; Determination of optimum levels of spray dried porcine plasma (SDPP) in diets for weanling pigs. Journal of Animal Science. v.69, p.369, $1991 \mathrm{a}$. Supplement, 1 .

GATNAU, R.; ZIMMERMAN, D.R. Spray dried porcine plasma (SDPP) as a source of protein for weanling pigs in two environments. Journal of Animal Science. v. 69, p. 103, 1991 b. Supplement, 1 .

GATNAU, R.; ZIMMERMAN, D.R.; Determination of optimun levels of inclusion of spray-dried porcine plasma (SDPP) in diets for weanling pigs fed in pratical conditions. Journal of Animal Science. v. 70, p. 60,1992 . Supplement, 1.

GATNAU, R.; CAIN, C.; ARENTSON, R.; ZIMMERMAN, D.R. Spray-dried porcine plasma (SDPP) as an alternative ingredient in diets of weanling pigs. Pig News and Information. v. 14, n. 4, p. $157 \mathrm{~N}-159 \mathrm{~N}, 1993$.

GATNAU, R.; ZIMMERMAN, D.R. Effects of spray-dried plasma of different sources and processes on growth performance of weanling pigs. Journal of Animal Science. v.72, p. 166, 1994. Supplement, 1 . 
HANSEN, J.A.; GOODBAND, R.D.; NELSSEN, J.L.; FRIESEN, K.G.; WEEDEN, T.L.; Effect of substituting spray-dried porcine plasma protein for milk products in starter pig diets. Journal of Animal Science. v.69, p.103, 1991. Supplement,1.

HANSEN, J.A.; NELSSEN, J.L.; GOODBAND, R.D.; WEEDEN, T.L. Evaluation of animal protein supplements of early-weaned pigs. Journal of Animal Science. v.71, n. 7, p.1853-1862, 1993.

KATS, L.J.; TOKACH, M.D.; NELSSEN, J.L.; GOODBAND, R.D.; LAURIN, J.L. Comparison of spray-dried blood meal and fish by-products in the phase II starter pig diet. Kansas State University Swine Day Report. p.37-40, 1992.

KATS, L.J.; NELSSEN, J.L.; TOKACH, M.D.; GOODBAND, R.D.; WEEDEN, T.L.; DRITZ, S.S.; HANSEN, J.A.; FRESEN, K.G. The effects of spray-dried blood meal on growth performance of the early-weaned pig. Journal of Animal Science. v.72, n.11, p. $2860-2869,1994 \mathrm{a}$.

KATS, L.J.; NELSSEN, J.L.; TOKACH, M.D.; GOODBAND, R.D.; HANSEN, J.A.; LAURIN, J.L. The effect of spray-dried porcine plasma on growth performance in the early-weaned pig. Journal of Animal Science. v. 72, n. 8, p.2075-2081, 1994 b.

NATIONAL RESEARCH COUNCIL. Nutrient requirements of swine. National Academy Press, 1988.93p. 
OWEN, K.O.; NELSSEN, J.L.; TOKACH, M.D.; GOODBAND, R.D.; DRITZ, S.S.; KATS, L.J.; The effects of increasing level of lactose in a porcine plasma-based diet for the early weaned pig. Journal of Animal Science. v. 71, p. 175, 1993. Supplement, 1.

OWEN, K.Q.; NELSSEN, J.L.; GOODBAND, R.D.; TOKACH, M.D.; KATS, L.J.; FRIESEN, K.G. Added dietary methionine in starter pig diets containing spray-dried blood products. Journal of Animal Science. v.73, n.9, p.2647-2654, 1995 a.

OWEN, K.Q.; NELSSEN, J.L.; GOODBAND, R.D.; TOKACH, M.D.; FRIESEN, K.G.; RICHERT, B.T.; SMITH, J.W.; RUSSELL, L.E. Effects of various fractions of spray-dried porcine plasma on performance of early weaned pigs. Journal of Animal Science. v. 73, p.81, 1995b. Supplement, 1 .

PEKAS, J.C. Digestion and absorption capacity and their development. In: MILLER, E.R.; ULLREY, D.E.; LEWIS, A.J.(Ed.) Swine nutrition. Butterworth-Heinemann, 1991. cap. 3, p. 37-73.

PIERCE, J.L.; CROMWELL, G.L.; LINDEMANN, M.D.; COFFEY, R.D. Assessment of three fractions of spray-dried porcine plasma on performance of early-weaned pigs. Journal of Animal Science. v.73, p. 81, 1995. Supplement, 1 .

RICHERT B.T.; SMITH, J.W.; TOKACH, M.D.; GOODBAND, R.D.; NELSSEN, J.L. Comparison of norse LT-94 (Herring meal) to 
other protein sources in early-weaned starter pig diets. Kansas State University Swine Day Report. p.85-89, 1994.

RODAS, B.Z.; SOHN, K.S.; MAXWELL, C.V.; SPICER, L.J. Plasma protein for pigs weaned at 19 to 24 days of age: Effect on performance and plasma insulin-like growth factor I, growth hormone, insulin, and glucose concentration. Journal of Animal Science. v. 73, n.12, p. 3657-3665, 1995.

ROSTAGNO, H.S.; SILVA, D.J.; COSTA, P.M.A.; FONSECA, J.B.; SOARES, P.R.; Pereira, J.A.A.; Silva, M.A. Composição de alimentos e exigências nutricionais de aves e suínos (Tabelas brasileiras). Viçosa, Universidade Federal de Viçosa, Imprensa Universitária, 1983.59p.

RUSSELL, L.E. Effect of plasma source and processing method on postweaning performance of pigs. Journal of Animal Science. v. 72, p. 166,1994 . Supplement, 1 .

SAS INSTITUTE INC. SAS user's guide : estatistics. 5.ed. Cary: 1985.956p.

SGARBIERI, V.C. Proteínas em alimentos protéicos: propriedades, degradações, modificaçóes. Livraria Varela, $1996,517 \mathrm{p}$.

SMITH, J.W.; RICHERT, B.T.; GOODBAND, R.D., NELSSEN, J.L.; TOKACH, M.D.; KATS, L.J.; OWEN, K.Q.; DRITS, S.S. 
Evaluation of potato protein in starter pig diets. Kansas State University Swine Day Report. p.80-84, 1994.

SOHN, K.S.;MAXWELL, C.V.; BUCHANAN, D.S. Plasma protein as an alternative protein source for early weaned pigs. Journal of animal science. v. 69, p. 362,1991 . Supplement, 1 .

SWENSON, M.J. Propriedades fisiológicas e constituintes celulares e químicos do sangue. In: SWENSON, M.J. (Ed.) Dukes Fisiologia dos Animais Domésticos. Rio de Janeiro: Editora Guanabara, 1988. cap.2, p.13-34

THOMPSON, J.E.; JONES, E.E.; EISEN, E.J. Spray dried porcine plasma protein enhances feed intake, growth rate and efficiency of gain in mice. Journal of Animal Science. v.71, p.175, 1993. Supplement, 1.

TOUCHeTte, K.J.; ALlEe, G.L.; NEWCOMB, M.D. The effects of plasma, lactose, and soy protein source fed in a phase I diet on nursery performance. Journal of Animal Science. v.74, p.170, 1996. Supplement, 1.

WEAVER, E.M.; RUSSELL, L.E.; DREW, M.D. The effect of spraydried animal plasma fractions on performance of newly weaned pigs. Journal of Animal Science. v.73, p.81, 1995 Supplement, 1 . 
APÊNDICE 
Tabela A1. Resultados de performance dos leitões em recria na primeira semana experimental.

\begin{tabular}{|c|c|c|c|c|c|}
\hline \multirow[b]{2}{*}{ Item ${ }^{a}$} & \multirow[b]{2}{*}{ Bloco } & \multicolumn{4}{|c|}{ Níveis de inclusão de plasma, $\%$} \\
\hline & & 0 & 2,5 & 5,0 & 7,5 \\
\hline \multirow{6}{*}{ GDP. $g$} & 1 & 257 & 243 & 319 & 291 \\
\hline & 2 & 130 & 282 & 304 & 248 \\
\hline & 3 & 267 & 217 & 260 & 215 \\
\hline & 4 & 155 & 226 & 230 & 288 \\
\hline & 5 & 262 & 275 & 204 & 277 \\
\hline & média & $2 \overline{14}$ & $2 \overline{9}$ & $26 \overline{3}$ & $\overline{2} \overline{6} \overline{4}$ \\
\hline \multirow{6}{*}{ CDR, $\mathrm{g}$} & 1 & 298 & 298 & 352 & 310 \\
\hline & 2 & 176 & 291 & 160 & 255 \\
\hline & 3 & 288 & 283 & 291 & 298 \\
\hline & 4 & 183 & 245 & 276 & 326 \\
\hline & 5 & 283 & 271 & 233 & 377 \\
\hline & média & 246 & 278 & $26 \overline{3}$ & 313 \\
\hline \multirow{6}{*}{ C.A. } & 1 & 1,16 & 1,23 & 1,10 & 1,07 \\
\hline & 2 & 1,36 & 1,03 & 0,65 & 1,03 \\
\hline & 3 & 1,08 & 1,31 & 1,12 & 1,38 \\
\hline & 4 & 1,18 & 1,08 & 1,20 & 1,13 \\
\hline & 5 & 1,08 & 0,99 & 1,18 & 1,16 \\
\hline & média & $1, \overline{17}$ & 1,13 & 1,05 & $\overline{1}, \overline{15}$ \\
\hline
\end{tabular}

a - GDP = ganho diário de peso, $C D R=$ consumo diário de ração e $C A$ = conversão alimentar. 
Tabela A2. Resultados de performance dos leitões em recria na segunda semana experimental ( 7 a 14 dias).

\begin{tabular}{|c|c|c|c|c|c|}
\hline \multirow[b]{2}{*}{ Item $^{a}$} & \multirow[b]{2}{*}{ Bloco } & \multicolumn{4}{|c|}{ Níveis de inclusão de plasma. \% } \\
\hline & & 0 & 2,5 & 5,0 & 7,5 \\
\hline \multirow{6}{*}{ GDP, $g$} & 1 & 543 & 502 & 531 & 469 \\
\hline & 2 & 331 & 443 & 432 & 421 \\
\hline & 3 & 533 & 457 & 479 & 467 \\
\hline & 4 & 350 & 429 & 460 & 443 \\
\hline & 5 & 298 & 364 & 380 & 445 \\
\hline & médià & 411 & 439 & $45 \overline{6}$ & $\overline{449}$ \\
\hline \multirow{6}{*}{ CDR, g } & 1 & 707 & 757 & 802 & 741 \\
\hline & 2 & 495 & 638 & 603 & 664 \\
\hline & 3 & 714 & 562 & 724 & 655 \\
\hline & 4 & 510 & 655 & 645 & 714 \\
\hline & 5 & 548 & 581 & 545 & 726 \\
\hline & média & $5 \overline{95}$ & 639 & 664 & 700 \\
\hline \multirow{6}{*}{ C.A. } & 1 & 1,30 & 1,51 & 1,51 & 1,58 \\
\hline & 2 & 1,50 & 1,44 & 1,44 & 1,58 \\
\hline & 3 & 1,34 & 1,23 & 1,51 & 1,40 \\
\hline & 4 & 1,46 & 1,53 & 1,40 & 1.61 \\
\hline & 5 & 1,73 & 1,59 & 1,51 & 1,46 \\
\hline & média & $1, \overline{7}$ & 1,46 & 1,47 & 1,53 \\
\hline
\end{tabular}

\footnotetext{
a - GDP $=$ ganho diário de peso, CDR = consumo diário de ração e CA = conversão alimentar.
} 
Tabela A3. Resultados de performance dos leitões em recria na terceira semana experimental ( 14 a 21 dias).

\begin{tabular}{|c|c|c|c|c|c|}
\hline \multirow[b]{2}{*}{ Item ${ }^{a}$} & \multirow[b]{2}{*}{ Bloco } & \multicolumn{4}{|c|}{ Níveis de inclusão de plasma. \% } \\
\hline & & 0 & 2.5 & 5,0 & 7,5 \\
\hline \multirow{6}{*}{ GDP, $\mathrm{g}$} & 1 & 593 & 686 & 550 & 564 \\
\hline & 2 & 586 & 543 & 554 & 531 \\
\hline & 3 & 610 & 598 & 588 & 626 \\
\hline & 4 & 429 & 550 & 586 & 550 \\
\hline & 5 & 523 & 531 & 459 & 414 \\
\hline & média & $\overline{54 \overline{8}}$ & $5 \overline{8} \overline{1}$ & $\overline{547}$ & $\overline{537}$ \\
\hline \multirow{6}{*}{ CDR. $\mathrm{g}$} & 1 & 1057 & 1183 & 1119 & 1117 \\
\hline & 2 & 910 & 1000 & 1077 & 988 \\
\hline & 3 & 1190 & 1114 & 1110 & 1114 \\
\hline & 4 & 950 & 1052 & 1093 & 1136 \\
\hline & 5 & 924 & 964 & 902 & 1057 \\
\hline & média & 1006 & 1063 & $10 \overline{60}$ & 1082 \\
\hline \multirow{6}{*}{ C. A. } & 1 & 1,78 & 1,73 & 2,03 & 1,99 \\
\hline & 2 & 1.55 & 1,84 & 2,05 & 1,86 \\
\hline & 3 & 1,95 & 1,87 & 1,89 & 1,78 \\
\hline & 4 & 2,22 & 1,91 & 1,87 & 2.07 \\
\hline & 5 & 1,70 & 1,82 & 2,11 & 2.19 \\
\hline & média & $\overline{1}, \overline{84}$ & $\overline{1}, \overline{8}$ & $1, \overline{99}$ & 1,98 \\
\hline
\end{tabular}

${ }^{a}$ - GDP = ganho diário de peso, $C D R=$ consumo diário de raçào e CA = conversão alimentar. 
Tabela A4. Resultados de performance dos leitões em recria na quarta semana experimental ( 21 a 28 dias).

\begin{tabular}{|c|c|c|c|c|c|}
\hline \multirow[b]{2}{*}{ Item $^{a}$} & \multirow[b]{2}{*}{ Bloco } & \multicolumn{4}{|c|}{ Níveis de inclusão de plasma, $\%$} \\
\hline & & 0 & 2,5 & 5,0 & 7.5 \\
\hline \multirow{6}{*}{ GDP, $\mathrm{g}$} & 1 & 721 & 814 & 862 & 745 \\
\hline & 2 & 617 & 660 & 633 & 600 \\
\hline & 3 & 750 & 721 & 667 & 736 \\
\hline & 4 & 529 & 721 & 710 & 681 \\
\hline & 5 & 641 & 583 & 561 & 663 \\
\hline & média & $6 \overline{5} 2$ & 700 & 686 & 685 \\
\hline \multirow{6}{*}{ CDR. $\mathrm{g}$} & 1 & 1186 & 1364 & 1367 & 1255 \\
\hline & 2 & 981 & 1050 & 1029 & 995 \\
\hline & 3 & 1217 & 1150 & 1221 & 1190 \\
\hline & 4 & 907 & 1124 & 1186 & 1140 \\
\hline & 5 & 938 & 952 & 955 & 1049 \\
\hline & média & 1046 & 1128 & $11 \overline{1}$ & 1126 \\
\hline \multirow{6}{*}{ C.A. } & 1 & 1.64 & 1,68 & 1,59 & 1,68 \\
\hline & 2 & 1.59 & 1,59 & 1,68 & 1,66 \\
\hline & 3 & 1.62 & 1,59 & 1,83 & 1.62 \\
\hline & 4 & 1.72 & 1,56 & 1,67 & 1.68 \\
\hline & 5 & 1,46 & 1,63 & 1,76 & 1.60 \\
\hline & média & 1,61 & 1,61 & $1,7 \overline{1}$ & 1,65 \\
\hline
\end{tabular}

a $-G D P=$ ganho diário de peso, $C D R=$ consumo diário de ração e $C A=$ conversão alimentar. 
Tabela A5. Resultados de performance dos leitões em recria nas duas primeiras semanas experimentais ( 0 a 14 dias).

\begin{tabular}{|c|c|c|c|c|c|}
\hline \multirow[b]{2}{*}{ Item $^{a}$} & \multirow[b]{2}{*}{ Bloco } & \multicolumn{4}{|c|}{ Níveis de inclusão de plasma. $\%$} \\
\hline & & 0 & 2,5 & 5,0 & 7.5 \\
\hline \multirow{6}{*}{ GDP, $\mathrm{g}$} & 1 & 400 & 373 & 425 & 380 \\
\hline & 2 & 230 & 363 & 368 & 335 \\
\hline & 3 & 400 & 337 & 369 & 341 \\
\hline & 4 & 252 & 327 & 345 & 365 \\
\hline & 5 & 280 & 320 & 292 & 361 \\
\hline & média & $31 \overline{3}$ & $34 \overline{4}$ & $\overline{360}$ & 356 \\
\hline \multirow{6}{*}{ CDR. $g$} & 1 & 502 & 527 & 577 & 525 \\
\hline & 2 & 336 & 464 & 381 & 460 \\
\hline & 3 & 501 & 423 & 507 & 476 \\
\hline & 4 & 346 & 450 & 461 & 520 \\
\hline & 5 & 415 & 426 & 389 & 551 \\
\hline & média & 420 & 458 & 463 & $50 \overline{7}$ \\
\hline \multirow{6}{*}{ C.A. } & 1 & 1,26 & 1,42 & 1,36 & 1,38 \\
\hline & 2 & 1,46 & 1,28 & 1,15 & 1,37 \\
\hline & 3 & 1.25 & 1.25 & 1.37 & 1,40 \\
\hline & 4 & 1,37 & 1,38 & 1,34 & 1,42 \\
\hline & 5 & 1,43 & 1,33 & 1,39 & 1,34 \\
\hline & média & 1,35 & 1,33 & 1,32 & 1,38 \\
\hline
\end{tabular}

a $-\mathrm{GDP}=$ ganho diário de peso, $\mathrm{CDR}=$ consumo diário de ração e $\mathrm{CA}=$ conversão alimentar. 
Tabela A6. Resultados de performance dos leitões em recria nas três semanas experimentais ( 0 a 21 dias).

\begin{tabular}{|c|c|c|c|c|c|}
\hline \multirow[b]{2}{*}{ Item $^{a}$} & \multirow[b]{2}{*}{ Bloco } & \multicolumn{4}{|c|}{ Níveis de inclusão de plasma, \% } \\
\hline & & 0 & 2,5 & 5,0 & 7,5 \\
\hline \multirow{6}{*}{ GDP, g } & 1 & 464 & 477 & 467 & 441 \\
\hline & 2 & 349 & 423 & 430 & 400 \\
\hline & 3 & 470 & 424 & 442 & 436 \\
\hline & 4 & 311 & 402 & 425 & 427 \\
\hline & 5 & 361 & 390 & 348 & 379 \\
\hline & média & 391 & 423 & 422 & $\overline{417}$ \\
\hline \multirow{6}{*}{ CDR. $\mathrm{g}$} & 1 & 687 & 746 & 758 & 722 \\
\hline & 2 & 527 & 643 & 613 & 636 \\
\hline & 3 & 731 & 653 & 708 & 689 \\
\hline & 4 & 548 & 651 & 671 & 725 \\
\hline & 5 & 585 & 606 & 560 & 720 \\
\hline & média & 616 & 660 & 662 & 698 \\
\hline \multirow{6}{*}{ C. A. } & 1 & 1,48 & 1,56 & 1,62 & 1,64 \\
\hline & 2 & 1,51 & 1,52 & 1,55 & 1,59 \\
\hline & 3 & 1.56 & 1,54 & 1,60 & 1,58 \\
\hline & 4 & 1,76 & 1,62 & 1,58 & 1,70 \\
\hline & 5 & 1,56 & 1,55 & 1,70 & 1.65 \\
\hline & média & 1,57 & 1,56 & 1,61 & 1,63 \\
\hline
\end{tabular}

a $-\mathrm{GDP}=$ ganho diário de peso, $\mathrm{CDR}=$ consumo diário de ração e CA = conversão alimentar. 
Tabela A7. Resultados de performance dos leitões em recria nas quatro semanas experimentais ( 0 a 28 dias).

\begin{tabular}{|c|c|c|c|c|c|}
\hline \multirow[b]{2}{*}{ Item ${ }^{a}$} & \multirow[b]{2}{*}{ Bloco } & \multicolumn{4}{|c|}{ Níveis de inclusão de plasma. \% } \\
\hline & & 0 & 2,5 & 5,0 & 7,5 \\
\hline \multirow{6}{*}{ GDP, g } & 1 & 529 & 561 & 565 & 517 \\
\hline & 2 & 416 & 482 & 481 & 450 \\
\hline & 3 & 540 & 498 & 498 & 511 \\
\hline & 4 & 366 & 482 & 496 & 491 \\
\hline & 5 & 431 & 438 & 401 & 450 \\
\hline & média & $4 \overline{5} \overline{6}$ & 492 & 488 & $-\overline{484}$ \\
\hline \multirow{6}{*}{ CDR, g } & 1 & 812 & 901 & 910 & 855 \\
\hline & 2 & 641 & 745 & 717 & 726 \\
\hline & 3 & 852 & 777 & 836 & 814 \\
\hline & 4 & 638 & 769 & 800 & 829 \\
\hline & 5 & 673 & 692 & 659 & 802 \\
\hline & média & $7 \overline{2} \overline{3}$ & $\overline{77} \overline{7}$ & 784 & 805 \\
\hline \multirow{6}{*}{ C. A. } & 1 & 1,54 & 1,60 & 1,61 & 1,65 \\
\hline & 2 & 1.54 & 1,55 & 1,59 & 1,61 \\
\hline & 3 & 1.58 & 1,56 & 1,68 & 1,59 \\
\hline & 4 & 1,74 & 1,60 & 1,61 & 1,69 \\
\hline & 5 & 1,53 & 1,58 & 1,72 & 1,64 \\
\hline & média & $1 . \overline{59}$ & 1,58 & 1,64 & $\overline{1}, \overline{64}$ \\
\hline
\end{tabular}

a $-\mathrm{GDP}=$ ganho diário de peso, $\mathrm{CDR}=$ consumo diario de ração e CA = conversão alimentar 
Tabela A8. Resultados de performance dos leitões em recria durante as duas últimas semanas experimentais (14 a 28 dias).

\begin{tabular}{|c|c|c|c|c|c|}
\hline \multirow[b]{2}{*}{ Item $^{a}$} & \multirow[b]{2}{*}{ Bloco } & \multicolumn{4}{|c|}{ Níveis de inclusão de plasma. \% } \\
\hline & & 0 & 2.5 & 5,0 & 7.5 \\
\hline \multirow{6}{*}{ GDP,$g$} & 1 & 657 & 750 & 706 & 655 \\
\hline & 2 & 601 & 601 & 593 & 566 \\
\hline & 3 & 680 & 660 & 627 & 681 \\
\hline & 4 & 479 & 636 & 648 & 616 \\
\hline & 5 & 582 & 557 & 510 & 538 \\
\hline & média & 600 & $\overline{64} \overline{1}$ & $\overline{6} \overline{1} \overline{7}$ & $\overline{6} \overline{1}$ \\
\hline \multirow{6}{*}{ CDR, g } & 1 & 1121 & 1274 & 1243 & 1186 \\
\hline & 2 & 945 & 1025 & 1053 & 992 \\
\hline & 3 & 1204 & 1132 & 1166 & 1152 \\
\hline & 4 & 929 & 1088 & 1139 & 1138 \\
\hline & 5 & 931 & 958 & 929 & 1053 \\
\hline & média & 1026 & 1096 & 1106 & 1104 \\
\hline \multirow{6}{*}{ C. A. } & 1 & 1,71 & 1,70 & 1,76 & 1,81 \\
\hline & 2 & 1,57 & 1,71 & 1,85 & 1,75 \\
\hline & 3 & 1,77 & 1,72 & 1,86 & 1,69 \\
\hline & 4 & 1,94 & 1,71 & 1,76 & 1,85 \\
\hline & 5 & 1,57 & 1,72 & 1,91 & 1,85 \\
\hline & média & 1,71 & 1,71 & $1, \overline{8}$ & $\overline{1,79}$ \\
\hline
\end{tabular}

a $-\mathrm{GDP}=$ ganho diário de peso. $\mathrm{CDR}=$ consumo diário de ração e $\mathrm{CA}=$ conversão alimentar. 
Tabela A9. Peso médio dos blocos dos tratamentos em cada período experimental.

\begin{tabular}{ccccccc}
\hline & & \multicolumn{5}{c}{ Período experimental, dias } \\
\cline { 2 - 7 } & Bloco & 0 & 7 & 14 & 21 & 28 \\
\hline \multirow{3}{*}{ Peso Médio, kg } & 1 & 6,729 & 8,671 & 12,250 & 16,438 & 21,938 \\
& 2 & 5,631 & 7,317 & 10,165 & 14,038 & 18,429 \\
& 3 & 5,973 & 7,650 & 11,038 & 15,275 & 20,304 \\
& 4 & 5,573 & 7,146 & 10,088 & 13,788 & 18,408 \\
& 5 & 4,855 & 6,634 & 9,238 & 12,610 & 16,894 \\
\hline
\end{tabular}

